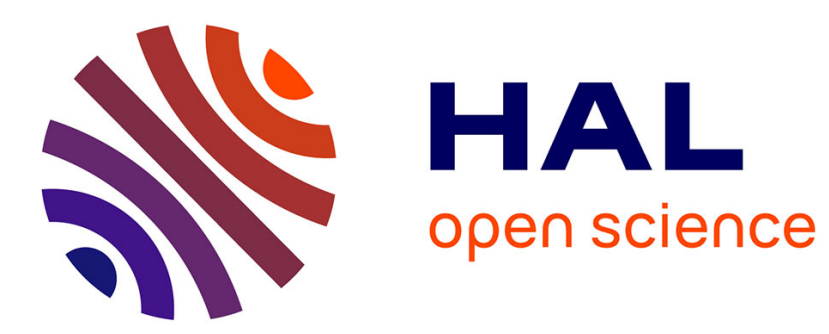

\title{
Isoflavone production in hairy root cultures and plantlets of Trifolium pratense
}

Andressa Reis, Stéphanie Boutet-Mercey, Sophie Massot, Pascal Ratet, José Angelo Silveira Zuanazzi

\section{- To cite this version:}

Andressa Reis, Stéphanie Boutet-Mercey, Sophie Massot, Pascal Ratet, José Angelo Silveira Zuanazzi. Isoflavone production in hairy root cultures and plantlets of Trifolium pratense. Biotechnology Letters, 2019, 41, pp.427-442. 10.1007/s10529-018-02640-8 . hal-03052681

\section{HAL Id: hal-03052681 \\ https://hal.science/hal-03052681}

Submitted on 10 Dec 2020

HAL is a multi-disciplinary open access archive for the deposit and dissemination of scientific research documents, whether they are published or not. The documents may come from teaching and research institutions in France or abroad, or from public or private research centers.
L'archive ouverte pluridisciplinaire HAL, est destinée au dépôt et à la diffusion de documents scientifiques de niveau recherche, publiés ou non, émanant des établissements d'enseignement et de recherche français ou étrangers, des laboratoires publics ou privés. 


\section{Section of the Journal - Plant Cell Technology}

2

3 Isoflavone production in hairy root cultures and plantlets of Trifolium pratense

4

5 Andressa Reis ${ }^{1}$, Stéphanie Boutet-Mercey ${ }^{2}$, Sophie Massot ${ }^{3-4}$, Pascal Ratet ${ }^{*-4}$, José Angelo

6 Silveira Zuanazzi ${ }^{1}$.

7

$8 \quad{ }^{1}$ Laboratory of Pharmacognosy, Department of Raw Material Production - Federal University

9 of Rio Grande do Sul, Porto Alegre - UFRGS, 90610-000, Brazil.

$10{ }^{2}$ Institut Jean-Pierre Bourgin, INRA, AgroParisTech, CNRS, Université Paris-Saclay, 78000,

11 Versailles, France.

$12{ }^{3}$ Institute of Plant Sciences Paris-Saclay IPS2, CNRS, INRA, Université Paris-Sud, Université 13 Evry, Université Paris-Saclay, Bâtiment 630, 91405, Orsay, France.

$14{ }^{4}$ Institute of Plant Sciences Paris-Saclay IPS2, Paris Diderot, Sorbonne Paris-Cité, Bâtiment 15 630, 91405, Orsay, France.

16

17 * Corresponding author: pascal.ratet@ips2.universite-paris-saclay.fr; Phone number: + 33

$18 \quad(0) 1.69 .15 .33 .77$. 


\section{Abstract}

2

3 Objectives

4 The aim of this study was to develop a T. pratense hairy root (HR) production protocol and

5 select HR lines with high isoflavone yield following elicitor treatments.

$6 \quad$ Results

7 We obtained 13 independent HR lines, producing approximately 3 times more isoflavonoids 8 than seedlings $(3.3 \mathrm{mg} / \mathrm{g}$ dry weight $)$ and in which 27 isoflavonoids were detected. Each HR

9 line had its own isoflavonoid profile. These lines produced as major components daidzein,

10 genistein, formononetin and biochanin A. Sucrose, salicylic acid (SA), yeast extract (YE) and

11 flagellin 22 (flg22) were tested as elicitors. Using SA $140 \mathrm{mg} / \mathrm{L}$, allowed the maximum

12 isoflavonoid production in plantlets $(11.9 \mathrm{mg} / \mathrm{g}$ dry weight $)$ but reduced root growth, possibly

13 as a result of its toxicity. The highest isoflavone production in HR (27.9 mg/g dry weight) was

14 obtained using sucrose $60 \mathrm{~g} / \mathrm{L}$, for 3.5 days.

15 Conclusion

16 This work reports the high production of various isoflavonoids with $T$. pratense elicited HR 17 cultures.

18

19 Keywords: Elicitors; plantlets; red clover; salicylic acid; sucrose. 


\section{Introduction}

Red clover (Trifolium pratense L.) is a forage legume producing as main isoflavones

3 formononetin, biochanin A, daidzein and genistein (Fig.1-A to D) (Saviranta et al. 2008).

4 These molecules present several biological activities related to their phytoestrogenic-like

5 activy, due to some similarities with the structure of $17 \beta$-estradiol (Fig. 1-e) (Monteiro et al. $62018)$.

7

\section{Insert Fig. 1}

These economically interesting plant secondary metabolites generally accumulate in roots (Saviranta et al. 2010). To avoid destroying the plant, the Agrobacterium rhizogenes transformed hairy root (HR) cultures represent a good alternative for biotechnological applications (Guillon et al. 2006; Putalun et al. 2007).

HR cultures are cytologically stable, exhibit continued growth without any hormonal supplement, have negative gravitropism and produce opines. This stability allows biochemical and genetic manipulations (Webb et al. 1990) and the development of controlled cultures (Spagnuolo et al. 2014). To date, two studies have used red clover HR (Beach and Gresshoff 1986; Webb et al. 1990), but none of them focused on the secondary metabolites production.

Plants produce various natural products as part of their development or in response to elicitors that can be used to increase secondary metabolite production (Shinde et al. 2010; Udomsuk et al. 2011). Yeast extracts (YE, Saccharomyces cerevisiae) and salicylic acid (SA) can be used as elicitor in HR cultures (Ramirez-Estrada et al. 2016; Shinde et al. 2009b; Udomsuk et al. 2011). The bacterial flagellin or part of it (flg22 peptide) is also a potent elicitor, eliciting basal plant defenses in plants like Arabidopsis (Maffei et al. 2012; De Coninck et al. 2015). Sucrose has important signaling functions throughout all stages of the plant life cycle (Smeekens 2000; Sujatha and Kumari 2012). At high concentrations it can trigger reactive oxygen species production and also polyphenol, including anthocyanin, 
1 accumulation in grape (Vitis vinifera) (Ramakrishna and Ravishankar 2011) and also

2 flavonoids and anthocyanins production in A. thaliana (Solfanelli et al. 2006) .

3 The aim of our study was to develop a $T$. pratense hairy root (HR) production protocol

4 and select HR lines with high isoflavone yield following elicitor treatments. We report a

5 medium term (five months) study for the production of daidzein, genistein, formononetin and

6 biochanin A in HR culture.

$7 \quad$ Experimental

8

9

\section{Plant material}

Seeds of T. pratense var. URS-BRS Mesclador were donated by Dr. Miguel Dall'Agnol (UFRGS). The specimen was deposited under the registration code HAS 87114, number 4291 (10/14/1986) (Museum of Natural Sciences - Zoobotanic Foundation of Rio Grande do Sul). The harvest point is (latitude: $-30.0331 /$ longitude: -51.23 [err: \pm 29946 WGS84]).

\section{Seed disinfection and germination}

In order to initiate the in vitro germination process, $T$. pratense seeds were scarified with fine sandpaper and the disinfection process started with sodium hypochlorite ( $2 \%$ active chlorine) plus tween 20 (two drops/ $100 \mathrm{~mL}$ ) under stirring conditions for 30 minutes, followed by triple washes with sterile water and inoculation in agar/ water medium (agar $8 \mathrm{~g}$ $/ \mathrm{L})$. The seeds were maintained for 48 hours at $4{ }^{\circ} \mathrm{C}$ before their transfer to $24{ }^{\circ} \mathrm{C}$ (2 days) in the dark. The seedlings have started to grow at this point $( \pm 1.5 \mathrm{~cm}$ in length) and were shifted to a growth chamber with $16 \mathrm{~h}$ photoperiod $\left(200 \mu \mathrm{E} / \mathrm{s} / \mathrm{m}^{2}\right)$ in $1 / 2 \mathrm{MS}$ medium (Murashige and Skoog 1962) plus sucrose $10 \mathrm{~g} / \mathrm{L}$ and agar $7 \mathrm{~g} / \mathrm{L}$ (Supplementary material) . 
1 In order to test the elicitor effects on $T$. pratense development, the experiment was

2 initiated with 5 days-old $T$. pratense seedlings that were cultivated in the same conditions as

3 described above. The elicitation effect was measured at 0,12, 24, 36, 48 and 72, 96, 120 or

$4 \quad 168 \mathrm{~h}$ after inoculation.

5

6

\section{Elicitor preparation and treatment}

Elicitors treatment was tested using the Flagellin 22 peptide QRLSTGSRINSAKDDAAGLQIA (flg22, Proteogenix, Schiltigheim France), yeast extract (BD Biosciences), salicylic acid (Sigma Aldrich) and sucrose. The elicitor action was estimated as the percentage of root growth inhibition after treatment. Seedlings were grown on agar $7 \mathrm{~g} / \mathrm{L}$ or Phytagel ${ }^{\mathrm{TM}} 2 \mathrm{~g} / \mathrm{L}$ as gelling agents. Elicitors were dissolved in distilled sterile water and added to the medium in the following concentrations. Flg22 was used in the concentrations of $0 ; 0.25 ; 0.5 ; 1$ and $2.5 \mu \mathrm{M}$ (Millet et al. 2010). The YE (Supplementary material) was tested at $0.5 ; 1 ; 2 ; 3$ and $4 \mathrm{~g} / \mathrm{L}$ of medium. YE solution was filter sterilized and added after the medium sterilization (Sivesind and Seguin 2006). SA was dissolved in distilled water and autoclaved at $121{ }^{\circ} \mathrm{C}$ for $15 \mathrm{~min}$. After sterilization, SA was added at concentrations of 0, 1.4, 14, 70 and $140 \mathrm{mg} / \mathrm{L}$. Sucrose (Sigma Aldrich) was employed from 10, 30, 60, 90 until $180 \mathrm{~g} / \mathrm{L}$ and was autoclaved with the medium.

\section{Hairy root culture}

a) Agrobacterium culture and tissue infection

The A. rhizogenes strain A4TC24 (Petit et al. 1983) was cultured in the flask containing $4 \mathrm{ml}$ of YEB liquid medium + rifampicin $100 \mu \mathrm{g} / \mathrm{mL}$. The incubation was done at $30^{\circ} \mathrm{C}$, in a rotary shaker at $200 \mathrm{rpm}$. One day before the transformation, $100 \mu \mathrm{L}$ of the liquid culture was plated on a YEB agar plate with appropriated antibiotics. The culture was 
1 incubated overnight at $30^{\circ} \mathrm{C}$ to obtain a layer of $A$. rhizogenes on the plate to proceed with the

2 transformation.

3 The 7 days-old seedlings were infected aseptically by cutting the root meristem and 4 dipping it into the Agrobacterium layer or by wounding the principal root using 5 Agrobacterium-filled syringes. Inoculated seedlings were kept for two days in $1 / 2 \mathrm{MS}$, storing 6 the plate with an angle of $45^{\circ}$ and the root covered with opaque black plastic film. After this 7 time, the infected seedlings were transferred to $1 / 2 \mathrm{MS}+400 \mu \mathrm{g} / \mathrm{mL}$ Amoxicillin $\mathrm{Na}$ and

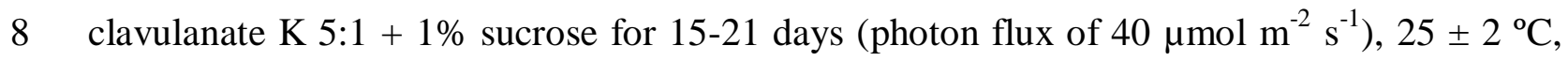
9 with the roots covered to remain in the dark (Wright and Wang 2015). When the new growing HR reached the size of $10-15 \mathrm{~cm}$, they were cut from the plant 11 and transferred to new medium, with the same components and sub cultured each thirty days.

12 Roots growing efficiently after two subcultures independently of the plant were considered as 13 true HR. These HR were transferred to Erlenmeyer flasks containing $50 \mathrm{~mL}$ of $1 / 2 \mathrm{MS}$ liquid medium and maintained at $20{ }^{\circ} \mathrm{C}$ on a shaker $(100 \mathrm{rpm})$ in the dark. These were also sub 15 cultured every 30 days.

17 The seedlings were grown for seven days using the media including the elicitors (sucrose + 18 phytagel, sucrose + agar, SA, YE and Flg22), as cited above (Elicitor preparation and 19 treatment section) and harvested for analysis. Thirteen HR lines with good growth capacities were isolated and partly harvested each 30 days of culture. The material was stored at $-80{ }^{\circ} \mathrm{C}$

21 for posterior flavonoids extraction and control of isoflavone content during the first 5 months 22 of the experiment. The flavonoids analysis by Ultra Performance in Liquid Chromatography (UPLC) was 24 adapted from the literature (Galland et al. 2014) and the samples were compared to standards 
1 of the commercially acquired isoflavones daidzein, genistein, formononetin and biochanin A

2 (Sigma-Aldrich). The hairy root cultures were lyophilized, and the extraction made using

3 around $100 \mathrm{mg}$ of $T$. pratense material reduced to powder using liquid nitrogen, mortar and

4 pestle. To this powder, $1.5 \mathrm{~mL}$ of extractive solution (methanol/ water/ acetone/ TFA, v/v 40/

$532 / 28 / 0.05 \%$ ) was added and the membranes were further disrupted by placing the samples

6 in an ultrasonic bath for $20 \mathrm{~min}$ at $25 \mathrm{kHz}$ at $4{ }^{\circ} \mathrm{C}$. These samples were then centrifuged at 20

$7000 \mathrm{~g}$ for $20 \mathrm{~min}$. The process of extraction was performed twice with the same sample and

8 the two resulting supernatants were pooled and dried in a rotary evaporator and freeze dryer.

9 The dry pellet was dissolved in acetonitrile $(\mathrm{ACN})$ : water $(1: 1 \mathrm{v} / \mathrm{v})$ and filtered in $22 \mu \mathrm{m}$ 10 (Millipore).

a) UPLC isoflavones quantitative analysis

The $T$. pratense HR culture and seedling extracts were analyzed by Acquity UPLC (Waters) equipped with a Waters Photodiode Array Detector e $\lambda$ UV detector. The separation of the compounds was achieved in a reverse phase (Acquity UPLC BEH C18, $1.7 \mu \mathrm{m}, 2.1 \mathrm{x}$ $50 \mathrm{~mm}$, Waters), using $3 \mu \mathrm{L}$ of each sample in a flow rate of $0.3 \mu \mathrm{L} / \mathrm{min}$, at $40{ }^{\circ} \mathrm{C}$ and a binary gradient: (A) water and formic acid $0.1 \%(\mathrm{~V} / \mathrm{V})$ and (B) ACN and formic acid $0.1 \%$

17 (V/V). The solvent gradient was programmed as follow: 0-2 min 5\% B, 2-4 min 10\% B, 4-17 $\mathrm{nm}$.

Quantitative analyzes were performed using commercial isoflavone standards to verify

21 the UV absorption, retention time and the linearity. Each curve was made with six different 22 concentrations. For daidzein the concentration range used was $1.5-5.5 \mu \mathrm{g} / \mathrm{mL}$, for genistein $234.3-216.4 \mu \mathrm{g} / \mathrm{mL}$, for formononetin $76.3-225 \mu \mathrm{g} / \mathrm{mL}$ and for biochanin A $5.9-357.2 \mu \mathrm{g}$ $24 / \mathrm{mL}$. The linear equation and the determination coefficient $\left(\mathrm{R}^{2}\right)$ were calculated for each 25 isoflavone standard curve. 
1

2

\section{b) Isoflavone identification}

The following flavonoid extraction protocol was adapted from the literature (Galland et al. 2014). HR flavonoids were extracted from $100 \mathrm{mg}$ of 13 different HR T. pratense lines cultivated for 60 days, after grounding in liquid nitrogen using mortar and pestle. Then, $1 \mathrm{ml}$ of methanol $80 \%(\mathrm{v} / \mathrm{v})$ was added to the HR powder samples and membranes were further ruptured by placing the samples in an ultrasonic bath for 20 min at $25 \mathrm{kHz}$ at $4{ }^{\circ} \mathrm{C}$ and later on a rotating wheel for 1 hour.

After centrifugation during $10 \mathrm{~min}$ at $20000 \mathrm{~g}$ at $4{ }^{\circ} \mathrm{C}$, the pellet was extracted with 1 $\mathrm{ml}$ of methanol $80 \%(\mathrm{v} / \mathrm{v})$ overnight at $4^{\circ} \mathrm{C}$ on a rotating wheel. The two resulting supernatants were pooled, filtered at $0.45 \mu \mathrm{m}$ (Millipore) and dried on a SpeedVac for $8 \mathrm{~h}$. The dry pellet was dissolved in methanol/ water/ acetone/ trifluoroacetic acid (40/32/28/0.05, v/v). At this stage, $20 \mathrm{ng}$ of rhamnetin (Extrasynthese) were added as internal standard. Finally, the extract was filtered again. The extracts were then analyzed by HPLCelectrospray-MSMS (HPLC-ESI-MS/MS).

The compounds were introduced in the ESI source using a Waters UPLC Acquity IClass (Waters) equipped with a Waters PDA detector. Separation was achieved on a reversephase column (Uptisphere C18 ODB, 150*2.1 mm, Interchim) using a flow rate of $0.40 \mathrm{~mL}$ /min and a binary gradient: (A) acetic acid $0.1 \%(\mathrm{v} / \mathrm{v})$ and (B) acetic acid $0.1 \%(\mathrm{v} / \mathrm{v})$ in acetonitrile. The solvent gradient was programmed as following: 0-4 min 10\% B, 4-17 min $60 \%$ B, 17-23 min 100\% B, 23-25 min 14\% B (Kerhoas et al. 2006).

Analyses were performed on a Waters Xevo TQ-S (Waters) MS triple quadripole mass spectrometer operating in MS full scan for the relative quantification and identification of the compounds, ESI positive and negative modes and In Source-Collision Induced Dissociation (IS-CID) positive modes. Relevant instrumental parameters were set as following: cone voltage $20 \mathrm{~V}$ and $80 \mathrm{~V}$ for usual and IS-CID modes respectively, capillary $2.70 \mathrm{kV}$, source 
1 block and desolvation gas temperatures $150^{\circ} \mathrm{C}$ and $600^{\circ} \mathrm{C}$, respectively. Nitrogen gas was

2 used to assist nebulization and desolvation (7 bar and $1000 \mathrm{~L} / \mathrm{h}$, respectively). When MS/MS

3 modes were used for the confirmation of the identification (Product ion scanning and

4 Precursor ion scanning $20 \mathrm{eV}$ was used as collision energy in the collision cell).

\section{Hairy root elicitation}

Elicitation was done on 5 months stabilized cultures. For this, approximately 7 days after subculture, hairy root cultures were transferred to $1 / 2$ MS medium containing: sucrose 10 $\mathrm{g} / \mathrm{L}$ (control) or sucrose $60 \mathrm{~g} / \mathrm{L}$ or sucrose $10 \mathrm{~g} / \mathrm{L}$ plus SA 10 or $30 \mathrm{mg} / \mathrm{L}$ as elicitors. The first measurements were done after 3 days (72 h) of culture and at 84, 96, 108 and $120 \mathrm{~h}(3.5,4$, 4.5 and 5 days, respectively). For control (sucrose $10 \mathrm{~g} / \mathrm{L}$ ), the measurements were done until the $14^{\text {th }}$ day in culture. The HR cultures were collected, lyophilized, grounded and extracted for total isoflavonoids measurement. The extraction and chemical analysis of isoflavones was performed according to the technique described in UPLC isoflavones quantitative analysis section.

\section{Statistical analysis}

All culture experiments were conducted in triplicate. The root length experiments were composed of different elicitor treatments at different concentrations. For each treatment 5 replicates of three plates were used, considering each plate as an experimental unit. HR cultures were run in quadruplicates for each line and the replicates of each line were combined in two, prior to isoflavones extraction and analysis. Elicitation of the HR cultures was performed in triplicates. Isoflavone concentrations were determined by means of the standard curves for each one of the isoflavones analyzed in the samples, as well as the standard deviation of the samples under study and Analysis of Variance (ANOVA) and Tukey test at 5\% significance level (Machado and Conceição 2002). 


\section{Results and discussion}

\section{Effect of elicitor on roots length and isoflavone content in T. pratense plantlets}

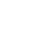

In order to estimate the effects of different elicitors on $T$. pratense, we tested their influence on seedling root growth and isoflavones content. Seedling root growth inhibition is easier to test than HR growth inhibition, because it is fast and easy to measure on many conditions. Compared to the control condition (sucrose $10 \mathrm{~g} / \mathrm{L}$ ) the different treatments either stimulated or inhibited root growth. We postulated that the elicitor action will mimic defense reactions and will inhibit root growth in these experiments. This was observed for high sucrose $(90$ and $120 \mathrm{~g} / \mathrm{L})$ and SA (140 mg/L) treatments. Root growth stimulation rather reflect a positive nutrition effect and was obtained in the treatments using YE $4 \mathrm{mg} / \mathrm{L}$ (106.4 $\mathrm{mm})$, which did not differ statistically from SA $1.4 \mathrm{mg} / \mathrm{L}(105.6 \mathrm{~mm})$, YE $1 \mathrm{mg} / \mathrm{L}$ (94 mm) and sucrose $60 \mathrm{~g} / \mathrm{L}+\operatorname{agar}(88.9 \mathrm{~mm})$ (Table S1-supplementary material).

These experiments were done using agar and phytagel as gelling agents. Roots were growing slightly better on phytagel with sucrose at $10 \mathrm{~g} / \mathrm{L}$ (Fig. 2-A), and similarly at 30 and $60 \mathrm{~g} / \mathrm{L}$. At sucrose concentration of 90 and $120 \mathrm{~g} / \mathrm{L}$ the root growth inhibition was less pronounced using agar as compared to phytagel.

\section{Insert Fig. 2}

Similarly, in Arabidopsis thaliana seedlings, sugar promoted growth at low concentrations, although, at high concentrations, it acts synergistically to abscisic acid to inhibit growth (León and Sheen 2003). Agar is routinely used as a gelling agent for tissue culture; however, it is known that depending on the sources from which it comes, it may

contain impurities interfering with the experiments (Cosson et al., 2006). Phytagel ${ }^{\mathrm{TM}}$, a selected grade of gelrite, is a very clean gelling agent, very effective in different applications (Veramendi et al. 1997). Despite that gelling agents should be inert constituents of the culture 
1 media (Arregui et al. 2003), in our red clover seedlings root length experiment phytagel and

2 agar were similar at low sugar concentration (until $60 \mathrm{~g} / \mathrm{L}$ ) but plants grew better on agar

3 (Figure 3-A) at higher sugar concentration.

4

\section{Insert Fig. 3}

This experiment (Fig. $3-A$, Table $\mathrm{S} 1$ ) shows that total $T$. pratense isoflavones content could be enhanced at high concentrations of sucrose in combination with agar, with a production reaching $11.3 \mathrm{mg} / \mathrm{g}$ dry weight using $120 \mathrm{~g} / \mathrm{L}$ of sucrose when it is only $3.2 \mathrm{mg} / \mathrm{g}$ dry weight using $10 \mathrm{~g} / \mathrm{L}$ sucrose. Using phytagel the best isoflavones production $(6 \mathrm{mg} / \mathrm{g}$ dry weight) was obtained with $90 \mathrm{~g} / \mathrm{L}$ of sucrose. Although the high sucrose and agar concentrations were the most effective, they were extremely damaging to the seedlings root growth (Fig. 2-A). Plantlets developed on phytagel showed a colour change at $90 \mathrm{~g} / \mathrm{L}$ of sucrose, with the formation of magenta colour near the cotyledons which correlated with the colour of the flavonoid extracts obtained from them (Fig. S1). Thus, our study also indicates that in $T$. pratense seedlings sucrose induces phenylpropanoid production with both an increase in anthocyanin and isoflavonoid production (Fig. 3-A and Fig. S1).

SA at low concentration $(1.4 \mathrm{mg} / \mathrm{mL}$; Fig. $2-B)$ increases root growth. At $14 \mathrm{mg} / \mathrm{mL}$ there is no change to control and at higher concentrations, root growth is inhibited. SA treatment did not change isoflavonoid production until the concentration reaches $140 \mathrm{mg} / \mathrm{L}$ (Fig. 3-B) by which the flavonoid amount almost tripled $(11.9 \mathrm{mg} / \mathrm{g}$ dry weight). Similar results were described with cell cultures and hairy root cultures of $P$. corylifolia (Shinde et al. 2009a) and for Phaseolus vulgaris cotyledons (Durango et al. 2013).

Contrary to sucrose and SA, YE (Fig. 2-C) had a rather positive effect on $T$. pratense seedling root growth. The isoflavonoids production in these YE treated roots decreased for 0.5 and $1 \mathrm{mg} / \mathrm{L}$ (Fig. 3-C), was similar to the control for $2 \mathrm{mg} / \mathrm{L}$ and increased slightly above the control for $4 \mathrm{mg} / \mathrm{L}$ YE. In studies with $P$. candollei HR cultures, YE was the most 
1 efficient elicitor for flavonoid production (Udomsuk et al. 2011) and in P. corylifolia cell

2 cultures and HR, YE was the best elicitor, inducing higher levels of daidzein and genistein in

3 both studies (Shinde et al. 2009a; Shinde et al. 2009b). Thus, in contrast to previous studies,

4 at the concentration used YE did not behave as an elicitor but rather promoted growth and

5 was not used further in our experiments.

Flagellin 22 (flg22) is a conserved 22-amino acid-long N-terminal part

7 (QRLSTGSRINSAKDDAAGLQIA) of the main bacterial flagellum protein that can act as a

8 potent biotic elicitor in plants. For $T$. pratense seedlings, the different concentrations tested

9 did not change root growth significantly (Fig. 2-D) but increased slightly isoflavonoids

10 production, using $0.5 \mu \mathrm{M} / \mathrm{L}$ (Fig. 3-D). As for YE, flagellin was not used further in our

11 experiment due to its poor elicitor effect on T. pratense.

All together isoflavonoid production was inversely related to the root growth inhibition (elicitor effect), validating the elicitor testing protocol, and the best effects were

14 obtained with SA and sucrose that multiplied isoflavonoid production by three.

Hairy roots are induced by the transfer to the plant recipient genome of the $A$.

17 rhizogenes T-DNA sequence containing plant oncogenes (Petit et al. 1983). These oncogenes

18 allow formation of root cultures that also produce opines. The transformed nature of the roots

19 is attested by the high HR growth rate in absence of hormones, their negative gravitropism

20 and the constancy in metabolite yield due to their genetic stability (Chandra and Chandra 21 2011).

T. pratense seedlings were infected with the A. rhizogenes strain A4TC24 five days 23 after germination. They showed visible adventitious root development 10 days after inoculation for about $90 \%$ of them, with root formation at the site of infection (Fig. 4-A). The 
1 putatively transformed roots were cut and transferred to solid medium (Fig. 4-B) where they

2 showed rapid growth and loss of the response to gravity (negative gravitropism; Fig. 4-C).

3 Rapid elongation is a phenotypic characteristic of such transformed roots, and the rapid lateral

4 branching is responsible for the increase in mass and accumulation of these roots (Eskandari-

5 Samet et al. 2012). When properly developed, the cultures were shifted to liquid culture

6 medium (Fig. 4-D) where the multiplication rate was exponential (Fig. 4- $E$ to $H$ ). All these

7 characteristics demonstrate that the root cultures obtained are true HR. Using this protocol,

8 thirteen $T$. pratense HR cultures were established and further studied.

9

10 Insert Fig. 4

a) Isoflavone identification

The thirteen HR cultures were harvested after the second month of culture to analyze their total isoflavonoids content by U-HPLC-ESI-MS/MS. According to these analyses 27 compounds were found in the chromatograms of the extracts obtained from these cultures (Table 1, compounds 1 to 27). Among these compounds it was possible to identify both aglycones and conjugated forms such as glycoside and glucoside malonates (Table 1 and Fig. 5), in agreement with studies done using Trifolium roots (Saviranta et al. 2010).

\section{Insert Fig. 5}

Fig. 5 shows that all the cultures were isoflavone producers, with the biochanin A (4) isomers as major compound representing 26.3 to $58.0 \%$ of the total isoflavonoid content. The second most abundant molecule was the formononetin aglycone (14), representing 10.1 to $36.5 \%$ of the compounds, followed by other isoflavonoids, such as irilone/ afrormosinemalonyl hexose $(\mathbf{9} ; 4.4$ to $17.7 \%)$ and biochanin isomers $(\mathbf{6} ; 6.7$ to $13.5 \%)$. Other molecules were produced in minor quantities and some of the cultures were unique in having certain molecules. For example, the HR10 culture was the only one to produce compounds $\mathbf{1 2}$ and $\mathbf{3}$, and the HR5 culture the only one producing compound 16. 
1 The HR cultures could be differentiated by their growth capacity and morphology, but

2 mainly by their biochemical production, demonstrating a high variability in isoflavonoids

3 types and content. These dissimilarities can result from genetic differences between the

4 seedlings used to start the HR cultures. Indeed T. pratense is an allogamous diploid plant and

$5 \quad$ individuals are genetically different.

6 Another important source of variation can be related to the effect of the A. rhizogenes

7 rol genes that can have different levels of expression between the different HR lines. This can

8 result in different auxins and cytokinins contents (or sensitivity) in each line (Fu et al. 2005).

9 These variations can produce differences in the accumulation patterns of secondary

10 metabolites as well as variations in growth rate and productivity between the clones. Previous

11 studies also showed that, even if the cultures come from a single root, they may present a

12 certain heterogeneity ( $\mathrm{Hu}$ and $\mathrm{Du} 2006)$.

b) Isoflavone content in the first five months of culture

In order to study the stability of the red clover root cultures isoflavone profiles during the first months after the transformation, four HR cultures (1HR, 2HR, 4HR and 6HR) were selected based on their good multiplication rate and stability. At the time of liquid culture subculture (each four weeks) part of the cultures were harvested and stored to analyze their isoflavonoids content. Lines $1 \mathrm{HR}, 2 \mathrm{HR}, 4 \mathrm{HR}$ and $6 \mathrm{HR}$ were then evaluated for their daidzein, genistein, formononetin and biochanin A content (Fig. 6- $A$ to $D$ and Table S2-Supplementary material). Fig. 6- $E$ shows the variations in the total isoflavone content of these molecules over time for these four HR cultures.

\section{Insert Fig. 6}

The most abundant isoflavones described in red clover are biochanin A (25) and formononetin (22), with the second being more present in roots (Saviranta et al. 2008). In contrast, the transformed root cultures analyzed here presented different most abundant 
1 metabolites. Line 4HR was the richest in daidzein $(27,1.73 \mathrm{mg} / \mathrm{g})$ at the end of the 150 days

2 (Fig. 6- $A$, Table S2). Genistein was produced in large quantities in line $2 \mathrm{HR}(1.01 \mathrm{mg} / \mathrm{g})$ at

3120 days of culture (Fig. 6-B, Table S2) and formononetin (22) in line 6HR (20.79 mg /g)

4 after 3 months of culture (Fig. 6-C, Table S2). Biochanin A (25) was the main compound

5 detected in line 4HR (13.90 mg /g) after 4 months in liquid medium (Fig. 6-D, Table S2).

The total isoflavones content was also estimated in these four lines. At the first point

7 measured (30 days, Table S2) the total isoflavonoid content of the four HR cultures was three

8 time higher than the seedling one (9.4 to $11.6 \mathrm{mg} / \mathrm{g}$ dry roots versus $3.2 \mathrm{mg} / \mathrm{g}$ dry plant, Table

$9 \mathrm{~S} 1$, sucrose $10 \mathrm{~g} / \mathrm{l}$ and Table S2). The isoflavone content even reached $27 \mathrm{mg}$ per $\mathrm{g}$ of dry root

10 in some cultures. Isoflavone production was stable for $1 \mathrm{HR}$ and $2 \mathrm{HR}$ over the 5 months of the

11 experiment. For $6 \mathrm{HR}$ an increase production was observed at month 3 and for line $4 \mathrm{HR}$

12 production increased months 4 and 5 (Fig. 6-E and Table S2). Previous studies did not

13 address isoflavone production over several months. However, they have shown that HR lines

14 can maintain genotypes and stability for extended periods, only loosing this ability with

15 drastic changes of the media or the addition of plant hormones that induce metabolic

16 modifications and cause disorganization in the cultures, as with Datura and Nicotiana

17 cultures (Doran 1997; Anil Kumar et al. 2018).

c) Elicitation of the isoflavonoid production

After the characterization, two lines, $4 \mathrm{HR}$ and $8 \mathrm{HR}$, were selected to conduct elicitation tests with sucrose 10 (control) and $60 \mathrm{~g} / \mathrm{L}$, as well as with salicylic acid 10 and 30 $\mathrm{mg} / \mathrm{L}$. After the treatment, the samples were harvested, stored and extracted for their evaluation in daidzein, genistein, formononetin, biochanin A and the total content of these four molecules using UPLC for a period of 3 to 14 days, depending on the sample analyzed.

In line 4HR grown in presence of sucrose $10 \mathrm{~g} / \mathrm{L}$ (Fig. 7-A) the isoflavone total concentration decreased during the culture from $11.21 \mathrm{mg} / \mathrm{g}$ at 3 days, down to $2.53 \mathrm{mg} / \mathrm{g}$ of 
1 dry mass in the end of 14 days in culture. The highest production for daidzein (27),

2 formononetin (22), biochanin A (25) and total isoflavones was observed 3 days after

3 treatment (Fig. 7-A) and decreased slowly during the experiment. In the case of genistein it

4 was 8 days after treatment.

\section{Insert Fig. 7}

For the line $8 \mathrm{HR}$ (Fig. $7-B$ ) the total isoflavones content at 3 days $(9.77 \mathrm{mg} / \mathrm{g})$ increased slightly at 4 days and decreased to $6.81 \mathrm{mg} / \mathrm{g}$ after 8 days. The time determined as best for the highest production was 4 days. The most abundant molecule for this control culture was biochanin A (25). The isoflavone production decreased after 4 days.

Based on these results, isoflavonoid production following elicitation was only studied for 4.5 days.

2 The use of $60 \mathrm{~g} / \mathrm{L}$ sucrose in line $4 \mathrm{HR}$ (Fig. 7-C) increased the total isoflavones production after 3.5 days of treatment to $27.88 \mathrm{mg} / \mathrm{g}$. This is 2.5 -fold the highest concentration (11.209 mg /g) measured for the control experiment and nearly 10 time more than in seedlings. Formononetin (22) increased 4 times, from $4.05 \mathrm{mg} / \mathrm{g}$ in control to 17.01 $\mathrm{mg} / \mathrm{g}$ but genistein production remained low. At 3.5 and 4 days of treatment daidzein (27) was produced in large amounts but at 4.5 days formononetin (22) was again the main compound.

Using sucrose at $60 \mathrm{~g} / \mathrm{L}$ for line $8 \mathrm{HR}$ (Fig. 7-D) resulted in a total isoflavones production peaking after 3.5 days of treatment to $21.21 \mathrm{mg} / \mathrm{g}$. Similarly, to what was observed in line $4 \mathrm{HR}$, the isoflavonoid production was different to the one observed in the control culture. Formononetin (22) instead of biochanin A (25) was the most abundant compound (14.76 mg /g) after 3.5 days of culture.

Different results were described in Pueraria phaseoloides transformed roots, where 30 $\mathrm{g} / \mathrm{L}$ sucrose promoted better accumulation of isoflavones after 16 days of treatment (Liang et 
1 al. 2004). In Hypericum perforatum L. root cultures, high quantities of sucrose were shown to

2 stimulate the production of total phenols and flavonoids (Cui et al. 2010), similar to what was

3 found in P. corylifolia root cultures, for which high concentrations, like $50 \mathrm{~g} / \mathrm{L}$, prolonged the

4 isoflavonoid biosynthesis and induced the accumulation even after more than 30 days of

5 culture (Shinde et al. 2010).

T. pratense hairy root cultures were tested using two SA concentrations (10 and 30

$7 \mathrm{mg} / \mathrm{L}$ ). The $4 \mathrm{HR}$ line was relatively insensitive to the $10 \mathrm{mg} / \mathrm{L}$ treatment (SA 10 treatment,

8 Fig. 7-E) with the best isoflavone production at 3 days $(11.64 \mathrm{mg} / \mathrm{g})$ similar to the control

9 one. In contrast, using $30 \mathrm{mg} / \mathrm{L}$ (SA 30 treatment, Fig. $7-G)$ the flavonoid content $(5.24 \mathrm{mg}$

$10 \mathrm{lg}$ ) at 3 days of culture was low as compared to control culture and declined close to zero at

11 the end of 4.5 days. In both cases the treatment did not change drastically the relative content

12 of the different molecules.

13 The $8 \mathrm{HR}$ line produced more isoflavonoid (17.17 $\mathrm{mg} / \mathrm{g}$ at 3 days) after the $10 \mathrm{mg} / \mathrm{L}$

14 treatment than the control (Fig. 7-F) but this production decreased rapidly to control level in

15 the next sampling time. In the $30 \mathrm{mg} / \mathrm{L}$ treatment the production was high $(12.20 \mathrm{mg} / \mathrm{g})$ at 3.5

16 days but reduced importantly later. Note that the isoflavonoids profiles were different from

17 the control experiment. In the SA 10 experiment the main difference to control in the

18 isoflavonoid composition was an increase in daidzein (27) content and the absence of

19 genistein. Formononetin $(\mathbf{2 2}, 4.67 \mathrm{mg} / \mathrm{g})$ and biochanin A $(\mathbf{2 5}, 5.74 \mathrm{mg} / \mathrm{g})$ were the most

20 abundant, at 3.5 days with SA 30 after elicitation. Their production decreased toward the end

21 of the experiment.

22 Our experiments thus show that the isoflavonoid production can be stimulated in the

23 T. pratense HR cultures by addition of sucrose $60 \mathrm{~g} / \mathrm{L}$ (Table S3-Supplementary material),

24 mainly for the 4HR line, increasing daidzein (27), formononetin (22) and the total isoflavones

25 content well above the values obtained with the seedlings. Note that genistein production was 
1 the highest using control sucrose condition (10 g/L). In contrast, SA treatment had rather

2 limited and short-term effects on isoflavonoid production, increasing only biochanin A (25)

3 production 3 days after the treatment. Higher SA concentration had rather negative effects.

4 This is in contrast to the $P$. corylifolia HR study for which isoflavonoid production was

5 independent of the SA concentration and of the length of the treatment (Udomsuk et al. 2011).

6 Similar results for the negative effect of the SA treatments were reported in another study

7 (Shinde et al. 2009b).

\section{$8 \quad$ Conclusion} pratense and studied their isoflavone content. Both the total or main aglycone isoflavones present in seedlings and HR cultures were determined and their production in the presence of elicitors tested. Seedlings had better root growth in the presence of salicylic acid $1.4 \mathrm{mg} / \mathrm{L}$ and yeast extract $4 \mathrm{mg} / \mathrm{L}$, but higher elicitor concentrations inhibited growth. The highest accumulation of total isoflavones in seedlings $(11.9 \mathrm{mg} / \mathrm{g}$ dry weight $)$ was found using SA $140 \mathrm{mg} / \mathrm{L}$. The independent hairy root cultures showed fast growth rates during the five months of the experiment and increased isoflavonoid production as compared to the seedling. Interestingly these cultures exhibited different isoflavonoid profiles and these profiles changed in the presence of elicitors, with high-level isoflavone production $(27.9 \mathrm{mg} / \mathrm{g}$ dry weight) when sucrose was added at $60 \mathrm{~g} / \mathrm{L}$ in the two lines analyzed.

Thus, these experiments showed that the use of A. rhizogenes strain A4TC24 mediated hairy root cultures in the presence of sucrose $60 \mathrm{~g} / \mathrm{L}$ could be used to produce different $T$. pratense isoflavonoids. The rather simple procedure described here can now be used as the starting point to establish large-scale cultures in bioreactors using amplification of cultures as described in Mehrotra et al., (2016) or for the manipulation of these cultures by expressing specific genes allowing overproduction of specific molecules. 
2 Notes

3

\section{Acknowledgements}

4 Thanks to the Coordination for the Improvement of Higher Education Personnel and National

5 Council for Scientific and Technological Development/ Brazil for the financial assistance

6 provided through $\mathrm{PhD}$ and Scientific Initiation scholarships. J.A.S.Z. thanks CNPq for the

7 researcher fellowship, Programa Iberoamericano CYTED - proyecto BIFRENES 416RT0511

8 and the National Institute of Science and Technology - INCT BioNat - grant \# 465637/2014-

9 0. Thanks also to Dr. Sandra Beatriz Rech, Dr. Miguel Dall'Agnol, Dr. Amelia Henriques and

10 Marí Castro for the collaboration. Thanks to Dr. Marie Garmier for careful reading and

11 editing of the manuscript. The Project benefits from the support of the LabEx Saclay Plant

12 Sciences-SPS (ANR-10-LABX-0040-SPS).

13

14 Compliance with ethical standards

15 Conflict of Interest: The authors declare that they have no conflict of interest.

16 Supplementary material

$17 \quad$ Media

18 All media were calculated for a volume of $1 \mathrm{~L}$ and were sterilized by autoclaving for 20 min at

$19120^{\circ} \mathrm{C}$. Antibiotics, hormones or other components, were added after autoclaving the media.

20 1. Media for plant culture

21 MS medium (Murashige and Skoog 1962): 
$14.49 \mathrm{~g}$ Murashige and Skoog medium basal salt mixture including vitamins and

2 microelements (Duchefa,), $30 \mathrm{~g}$ sucrose $\mathrm{pH}$ 5.8, $1 \%$ agar (Difco,) for solid medium. Sterilized

3 by autoclaving.

4 2. Media for bacterial culture

5 a) LB medium:

$65 \mathrm{~g}$ Yeast extract (Difco), $10 \mathrm{~g}$ Tryptone (Difco), $10 \mathrm{~g} \mathrm{NaCl}, 10 \mathrm{~g}$ agar (Difco) for solid 7 medium, $\mathrm{pH}$ 7.0. Sterilized by autoclaving.

8 b) YEB medium:

$95 \mathrm{~g}$ Beef extract (Difco), $1 \mathrm{~g}$ Yeast extract (Difco), $5 \mathrm{~g}$ Peptone (Difco), $5 \mathrm{~g}$ Sucrose, $2 \mathrm{mM}$ $10 \mathrm{MgSO}_{4}, \mathrm{pH}$ 7.2. Sterilized by autoclaving.

\section{References}

12 Anil Kumar M, Sravanthi Pammi SS, Sukanya MS, Giri A (2018) Enhanced production of pharmaceutically important isoflavones from hairy root rhizoclones of Trifolium pratense L. In Vitro Cell Dev Biol - Plant 1-10. doi: 10.1007/s11627-017-9873-y

Arregui LM, Veramendi J, Mingo-Castel AM (2003) Effect of gelling agents on in vitro tuberization of six potato cultivars. Amer J Potato Res 80:141-144.

Beach K, Gresshoff $\mathrm{P}$ (1986) In vitro culture of legume root tissue transformed by Agrobacterium rhizogenes. In: VI International Congress of Plant Tissue and Cell Culture. p 155

20 Chandra S, Chandra R (2011) Engineering secondary metabolite production in hairy roots. Phytochem Rev 10:371-395. doi: 10.1007/s11101-011-9210-8

22 Cosson V, Durand P, d'Erfurth I, Kondorosi A, Ratet P (2006) Medicago truncatula 
1 transformation using leaf explants, pp115-27 in Methods in Molecular Biology,

2 Agrobacterium protocols, Kan Wang editor, 343, Humana Press Inc. 999 Riverview

3 Drive, Suite 208 Totowa, New Jersey 07512.

4 Cui X, Chakrabarty D, Lee E, Paek K (2010) Production of adventitious roots and secondary

5 metabolites by Hypericum perforatum L. in a bioreactor. Bioresour Technol 101:4708-

6 4716. doi: $10.1016 /$ j.biortech.2010.01.115

7 De Coninck B, Timmermans P, Vos C, et al (2015) What lies beneath: Belowground defense

8 strategies in plants. Trends Plant Sci 20:91-101. doi: 10.1016/j.tplants.2014.09.007

9 Doran PM (1997) Hairy roots. CRC Press

10 Du H, Huang Y, Tang Y (2010) Genetic and metabolic engineering of isoflavonoid 11 biosynthesis. Appl Microbiol Biotechnol 86:1293-1312. DOI: 10.1007/s00253-010$2512-8$

13 Durango D, Pulgarin N, Echeverri F, et al (2013) Effect of salicylic acid and structurally related compounds in the accumulation of phytoalexins in cotyledons of common bean (Phaseolus vulgaris L.) cultivars. Molecules 18:10609-28. DOI:

17 Eskandari-Samet A, Piri K, Kayhanfar M, Hasanloo T (2012) Enhancement of tropane alkaloids production among several clones and explants types of hairy root of Atropa

Fu C, Zhao D, Xue X, et al (2005) Transformation of Saussurea involucrata by Agrobacterium rhizogenes: Hairy root induction and syringin production. 40:3789-3794. DOI: $10.1016 /$ j.procbio.2005.03.063

23 Galland M, Boutet-Mercey S, Lounifi I, et al (2014) Compartmentation and dynamics of 24 flavone metabolism in dry and germinated rice seeds. Plant Cell Physiol 55:1646-1659. DOI: $10.1093 / \mathrm{pcp} / \mathrm{pcu} 095$ 
1 Guillon S, Trémouillaux-Guiller J, Pati PK, et al (2006) Hairy root research: recent scenario and exciting prospects. Curr Opin Plant Biol 9:341-346. DOI: 10.1016/j.pbi.2006.03.008

3 Hu Z-B, Du M (2006) Hairy Root and Its Application in Plant Genetic Engineering. J Integr Plant Biol 48:121-127. DOI: 10.1111/j.1744-7909.2006.00121.x

Kanehisa M, Furumichi M, Tanabe M, et al (2017) KEGG: New perspectives on genomes, pathways, diseases and drugs. Nucleic Acids Res 45:D353-D361. DOI: 10.1093/nar/gkw1092

Kerhoas L, Aouak D, Cingöz A, et al (2006) Structural characterization of the major flavonoid glycosides from Arabidopsis thaliana seeds. J Agric Food Chem 54:66036612. DOI: $10.1021 / \mathrm{jf061043n}$

León P, Sheen J (2003) Sugar and hormone connections. Trends Plant Sci 8:110-116. DOI: $10.1016 / \mathrm{S} 1360-1385(03) 00011-6$

Liang P, Shi HP, Qi Y (2004) Effect of sucrose concentration on the growth and production of secondary metabolites in Pueraria phaseoloides hairy roots. Shi, Yan Sheng, Wu Xue, bao 37:384-390.

Machado and Conceição (2002) Programa estatístico WinStat Sistema de Análise Estatístico para Windows.

Maffei ME, Arimura G-I, Mithöfer A (2012) Natural elicitors, effectors and modulators of plant responses. Nat Prod Rep 29:1288. doi: 10.1039/c2np20053h

Mehrotra S, Mishra S, Srivastava V (2016) Bioreactor Technology for Hairy Roots Cultivation. In: Pavlov A., Bley T. (eds) Bioprocessing of Plant In Vitro Systems. Reference Series in Phytochemistry. Springer, Cham

Millet Y A, Danna CH, Clay NK, et al (2010) Innate Immune Responses Activated in Arabidopsis Roots by Microbe-Associated Molecular Patterns. Plant Cell 22:973-990. doi: $10.1105 /$ tpc. 109.069658 
1 Monteiro N, Queirós L, Lopes D, et al (2018) Impact of microbiota on the use and effects of

2 isoflavones in the relief of climacteric symptoms in menopausal women - A review. $\mathrm{J}$

$3 \quad$ Funct Foods 41:100-111. doi: 10.1016/j.jff.2017.12.043

4 Murashige T, Skoog F (1962) A revised medium for rapid growth and bio assays with tobacco tissue cultures. Physiol Plant 15:473-497. doi: doi: 10.1111/j.1399-3054.1962.tb08052.x

6 Petit A, David C, Dahl GA, et al (1983) Further extension of the opine concept: Plasmids in Agrobacterium rhizogenes cooperate for opine degradation. MGG Mol Gen Genet 190:204-214. doi: 10.1007/BF00330641

Putalun W, Luealon W, De-Eknamkul W, et al (2007) Improvement of artemisinin production by chitosan in hairy root cultures of Artemisia annua L. Biotech Lett 29:1143-1146. doi: $10.1007 / \mathrm{s} 10529-007-9368-8$

Ramakrishna A, Ravishankar GA (2011) Influence of abiotic stress signals on secondary metabolites in plants. Plant Signal Behav 6:1720-1731. doi: 10.4161/psb.6.11.17613

Ramirez-Estrada K, Vidal-Limon H, Hidalgo D, et al (2016) Elicitation, an effective strategy for the biotechnological production of bioactive high-added value compounds in plant cell factories. Molecules 21:182. doi: 10.3390/molecules21020182

Saviranta NM, Julkunen-Tiitto R, Oksanen E, Karjalainen RO (2010) Red clover (Trifolium pratense L.) isoflavones: root phenolic compounds affected by biotic and abiotic stress factors. J Sci Food Agric 90:418-423. doi: 10.1002/jsfa.3831

Saviranta NMM, Anttonen MJ, Wright A von, Karjalaianen RO (2008) Red clover (Trifolium pratense L.) isoflavones: determination of concentrations by plant stage, flower colour, plant part and cultivar. J Sci Food Agric 125-132. doi: 10.1002/jsfa

Shinde AN, Malpathak N, Fulzele DP (2010) Impact of nutrient components on production of the phytoestrogens daidzein and genistein by hairy roots of Psoralea corylifolia. J Nat Med 64:346-353. doi: 10.1007/s11418-010-0419-4 
1 Shinde AN, Malpathak N, Fulzele DP (2009a) Optimized production of isoflavones in cell

2 cultures of Psoralea corylifolia L. Using elicitation and precursor feeding. Biotechnol 3 Bioprocess Eng 14:612-618. doi: 10.1007/s12257-008-0316-9

4 Shinde AN, Malpathak N, Fulzele DP (2009b) Enhanced production of phytoestrogenic isoflavones from hairy root cultures of Psoralea corylifolia L. using elicitation and precursor feeding. Biotechnol Bioprocess Eng 14:612-618. doi: 10.1007/s12257-0080316-9

Sivesind E, Seguin P (2006) Effects of foliar application of elicitors on red clover isoflavone content. J Agron Crop Sci 192:50-54. doi: 10.1111/j.1439-037X.2006.00191.x

Smeekens S (2000) Sugar-induced signal transduction in plants. Stress Int J Biol Stress $51: 49-81$.

Solfanelli C, Solfanelli C, Poggi A, et al (2006) Sucrose-specific induction of the anthocyanin biosynthetic pathway in Arabidopsis. Plant Physiol 140:637-646. doi: 10.1104/pp.105.072579.the

Spagnuolo P, Rasini E, Luini A, et al (2014) Isoflavone content and estrogenic activity of different batches of red clover (Trifolium pratense L.) extracts: an in vitro study in MCF7 cells. Fitoterapia 94:62-69. doi: 10.1016/j.fitote.2014.01.027

Sujatha G, Kumari BR (2012) Establishment of fast-growing in vitro root culture system in Artemisia vulgaris. J Agric Technol 8:1779-1790.

Udomsuk L, Jarukamjorn K, Tanaka H, Putalun W (2011) Improved isoflavonoid production in Pueraria candollei hairy root cultures using elicitation. Biotechnol Lett 33:369-374. doi: $10.1007 / \mathrm{s} 10529-010-0417-3$

Veramendi J, Villafranca MJ, Sota V, Mingo-Castel AM (1997) Gelrite as an alternative to agar for micropropagation and microtuberization of Solanum tuberosum L. cv. Baraka. Vitr Cell Dev Biol - Plant 33:195-199. doi: 10.1007/s11627-997-0021-y 
1 Webb JK, Jones S, Robbins MP, Minchin FR (1990) Characterization of transgenic root 2 cultures of Trifolium repens, Trifolium pratense and Lotus corniculatus and transgenic 3 plants of Lotus corniculatus. Plant Sci 70:243-254.

4 Wright E, Wang Z-Y (2015) Medicago trunculata transformation using cotyledonary 5 explants. In: Wang K (ed) Agrobacterium protocols. Springer New York, New York, $6 \quad$ NY, pp 35-56

7

8 


\section{Tables Supplementary Material}

$\underline{\text { Table S1. Root growth (mm) and isoflavone content (mg /g dry plants) on T. pratense seedlings }}$ grown in medium with elicitors at different concentrations during the first seven days after germination*.

\begin{tabular}{|c|c|c|c|c|}
\hline Elicitor & Dosage & Total isoflavone & Root lenght (mm) & Standard deviation \\
\hline \multirow{5}{*}{$\begin{array}{c}\text { Sucrose + } \\
\operatorname{agar}(g / L)\end{array}$} & 10.0 & $3.20 \mathrm{D}$ & $67.9 \mathrm{EFG}$ & 0.163 \\
\hline & 30.0 & $5.75 \mathrm{CD}$ & 84.8 CDE & 0.227 \\
\hline & 60.0 & $5.76 \mathrm{CD}$ & 88.9 ABCD & 0.310 \\
\hline & 90.0 & $3.91 \mathrm{CD}$ & $47.7 \mathrm{G}$ & 0.334 \\
\hline & 120.0 & $11.34 \mathrm{AB}$ & $21.9 \mathrm{H}$ & 0.676 \\
\hline \multirow{5}{*}{ Sucrose + } & 10.0 & $3.24 \mathrm{D}$ & 76.6 CDEF & 0.440 \\
\hline & 30.0 & $2.35 \mathrm{D}$ & 85.4 BCDE & 0.088 \\
\hline & 60.0 & $2.3 \mathrm{D}$ & 82.9 CDE & 0.149 \\
\hline & 90.0 & 6.26 BCD & $20.7 \mathrm{H}$ & 0.205 \\
\hline & 120.0 & $3.09 \mathrm{D}$ & $12.2 \mathrm{H}$ & 0.337 \\
\hline \multirow{4}{*}{$\begin{array}{c}\text { Salicylic } \\
\text { acid } \\
(m g / L)\end{array}$} & 1.4 & $3.42 \mathrm{D}$ & $105.6 \mathrm{AB}$ & 0.144 \\
\hline & 14.0 & $3.28 \mathrm{D}$ & $60.3 \mathrm{FG}$ & 0.191 \\
\hline & 70.0 & $4.65 \mathrm{CD}$ & $16.7 \mathrm{H}$ & 0.095 \\
\hline & 140.0 & $11.90 \mathrm{~A}$ & $12.6 \mathrm{H}$ & 0.289 \\
\hline \multirow{4}{*}{$\begin{array}{c}\text { Flagellin } \\
22(\mu M / L)\end{array}$} & 0.25 & $4.13 \mathrm{CD}$ & 83.8 CDE & 0.089 \\
\hline & 0.50 & $5.59 \mathrm{CD}$ & 69.3 DEF & 0.112 \\
\hline & 1.0 & $2.33 \mathrm{D}$ & $70.8 \mathrm{DEF}$ & 0.118 \\
\hline & 2.0 & $4.26 \mathrm{CD}$ & 85.4 BCDE & 0.203 \\
\hline \multirow{4}{*}{$\begin{array}{c}\text { Yeast } \\
\text { extract } \\
(\mathrm{mg} / \mathrm{L})\end{array}$} & 0.5 & $2.59 \mathrm{D}$ & 77.0 CDEF & 0.088 \\
\hline & 1.0 & $2.51 \mathrm{D}$ & $94.0 \mathrm{ABC}$ & 0.074 \\
\hline & 2.0 & $3.35 \mathrm{D}$ & 82.9 CDE & 0.151 \\
\hline & 4.0 & $4.28 \mathrm{CD}$ & $106.4 \mathrm{~A}$ & 0.137 \\
\hline
\end{tabular}

\footnotetext{
$*$ Results are the mean of three replicates \pm SD and ANOVA followed by Tukey test at $5 \%$ of probability. Different letters for the same treatment are significantly different at $P<0.05$.
} 
Table S2. Isoflavones and total isoflavones content of the T. pratense HR lines 1HR, 2HR, 4HR and 6HR during the first 5 months of culture.

\begin{tabular}{|c|c|c|c|c|c|c|}
\hline Analysis & Culture & 30 days & 60 days & 90 days & 120 days & 150 days \\
\hline & $1 \mathrm{HR}$ & $0.48 \pm 0.22 \mathrm{C}$ & $0.90 \pm 0.11 \mathrm{~B}$ & $0.09 \pm 0.003 \mathrm{DE}$ & $0.00 \mathrm{E}$ & $0.21 \pm 0.053 \mathrm{DE}$ \\
\hline Daidzein (mg) g dry & $2 \mathrm{HR}$ & $0.00 \mathrm{E}$ & $0.43 \pm 0.02 \mathrm{C}$ & $0.00 \mathrm{E}$ & $0.00 \mathrm{E}$ & $0.71 \pm 0.116 \mathrm{~B}$ \\
\hline \multirow[t]{3}{*}{ roots) } & $4 \mathrm{HR}$ & $0.43 \pm 0.09 \mathrm{C}$ & $0.00 \mathrm{E}$ & $0.00 \mathrm{E}$ & $0.00 \mathrm{E}$ & $1.73 \pm 0.01 \mathrm{~A}$ \\
\hline & $6 \mathrm{HR}$ & $0.15 \pm 0.06 \mathrm{DE}$ & $0.27 \pm 0.01 \mathrm{CD}$ & $0.00 \mathrm{E}$ & $0.00 \mathrm{E}$ & $0.13 \pm 0.007 \mathrm{DE}$ \\
\hline & $1 \mathrm{HR}$ & $0.19 \pm 0.07 \mathrm{EF}$ & $0.19 \pm 0.05 \mathrm{EF}$ & $0.19 \pm 0.06 \mathrm{EF}$ & $0.49 \pm 0.06 \mathrm{C}$ & $0.24 \pm 0.04 \mathrm{DE}$ \\
\hline Genistein (mg/g dry & $2 \mathrm{HR}$ & $0.52 \pm 0.04 \mathrm{~B}$ & $0.00 \mathrm{G}$ & $0.00 \mathrm{G}$ & $1.01 \pm 0.001 \mathrm{~A}$ & $0.27 \pm 0.03 \mathrm{DE}$ \\
\hline \multirow[t]{3}{*}{ roots) } & $4 \mathrm{HR}$ & $0.13 \pm 0.06 \mathrm{~F}$ & $0.48 \pm 0.03 \mathrm{C}$ & $0.48 \pm 0.05 \mathrm{C}$ & $0.48 \pm 0.05 \mathrm{C}$ & $0.00 \mathrm{G}$ \\
\hline & $6 \mathrm{HR}$ & $0.32 \pm 0.04 \mathrm{D}$ & $0.23 \pm 0.01 \mathrm{DEF}$ & $0.69 \pm 0.01 \mathrm{~B}$ & $0.17 \pm 0.01 \mathrm{EF}$ & $0.00 \mathrm{G}$ \\
\hline & $1 \mathrm{HR}$ & $4.81 \pm 0.90 \mathrm{EF}$ & $1.16 \pm 0.24 \mathrm{JK}$ & $1.98 \pm 0.62 \mathrm{IJ}$ & $3.44 \pm 0.46 \mathrm{GH}$ & $3.04 \pm 0.35 \mathrm{HI}$ \\
\hline Formononetin (mg) & $2 \mathrm{HR}$ & $5.70 \pm 0.48 \mathrm{DE}$ & $5.48 \pm 0.18 \mathrm{E}$ & $2.68 \pm 0.18 \mathrm{HI}$ & $5.64 \pm 0.51 \mathrm{DE}$ & $5.35 \pm 0.73 \mathrm{EF}$ \\
\hline \multirow[t]{3}{*}{ g dry roots) } & $4 \mathrm{HR}$ & $6.78 \pm 0.06 \mathrm{D}$ & $4.27 \pm 0.03 \mathrm{FG}$ & $2.18 \pm 0.20 \mathrm{IJ}$ & $12.62 \pm 0.60 \mathrm{C}$ & $13.87 \pm 0.11 \mathrm{~B}$ \\
\hline & $6 \mathrm{HR}$ & $5.63 \pm 0.43 \mathrm{DE}$ & $5.12 \pm 0.32 \mathrm{EF}$ & $20.79 \pm 0.18 \mathrm{~A}$ & $1.14 \pm 0.08 \mathrm{JK}$ & $0.00 \mathrm{~K}$ \\
\hline & $1 \mathrm{HR}$ & $5.67 \pm 1.14 \mathrm{~B}$ & $1.47 \pm 0.67 \mathrm{E}$ & $1.43 \pm 0.71 \mathrm{EF}$ & $5.34 \pm 0.61 \mathrm{~B}$ & $2.97 \pm 0.73 \mathrm{CD}$ \\
\hline Biochanin A (mg) g & $2 \mathrm{HR}$ & $5.36 \pm 1.12 \mathrm{~B}$ & $1.61 \pm 0.29 \mathrm{DE}$ & $2.63 \pm 0.14 \mathrm{CDE}$ & $5.16 \pm 0.43 \mathrm{~B}$ & $2.78 \pm 0.27 \mathrm{CDE}$ \\
\hline \multirow[t]{2}{*}{ dry roots) } & $4 \mathrm{HR}$ & $3.36 \pm 0.36 \mathrm{C}$ & $2.29 \pm 0.002 \mathrm{CDE}$ & $3.22 \pm 0.28 \mathrm{C}$ & $13.90 \pm 0.46 \mathrm{~A}$ & $3.19 \pm 0.26 \mathrm{C}$ \\
\hline & $6 \mathrm{HR}$ & $5.00 \pm 0.35 \mathrm{~B}$ & $2.12 \pm 0.11 \mathrm{CDE}$ & $5.48 \pm 0.14 \mathrm{~B}$ & $1.56 \pm 0.09 \mathrm{DE}$ & $0.00 \mathrm{~F}$ \\
\hline
\end{tabular}




\begin{tabular}{|c|c|c|c|c|c|c|}
\hline & $1 \mathrm{HR}$ & $9.90 \pm 0.58 \mathrm{BCD}$ & $2.80 \pm 0.27 \mathrm{CD}$ & $2.51 \pm 0.35 \mathrm{CD}$ & $9.27 \pm 0.28 \mathrm{BCD}$ & $5.76 \pm 0.29 \mathrm{CD}$ \\
\hline Total isoflavone (mg/ & $2 \mathrm{HR}$ & $11.65 \pm 0.41 \mathrm{BC}$ & $5.41 \pm 0.12 \mathrm{CD}$ & $5.31 \pm 0.08 \mathrm{CD}$ & $11.30 \pm 0.23 \mathrm{BC}$ & $6.45 \pm 0.29 \mathrm{CD}$ \\
\hline \multirow[t]{2}{*}{ gdry roots) } & $4 \mathrm{HR}$ & $10.70 \pm 0.14 \mathrm{BCD}$ & $7.04 \pm 0.02 \mathrm{CD}$ & $5.62 \pm 0.12 \mathrm{CD}$ & $27.01 \pm 0.28 \mathrm{~A}$ & $18.79 \pm 0.09 \mathrm{AB}$ \\
\hline & $6 \mathrm{HR}$ & $9.36 \pm 0.22 \mathrm{BCD}$ & $7.49 \pm 0.11 \mathrm{BCD}$ & $26.96 \pm 0.08 \mathrm{~A}$ & $2.49 \pm 0.05 \mathrm{CD}$ & $0.13 \pm 0.002 \mathrm{D}$ \\
\hline
\end{tabular}

*Results are the mean of three replicates \pm SD and different letters in the same isoflavone detected are significantly different at $P<0.05$, using Tukey test. 


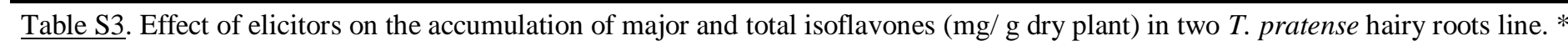

\begin{tabular}{|c|c|c|c|c|c|c|c|}
\hline Elicitor & HR line & Days & Daidzein & Genistein & Formononetin & Biochanin A & Total isoflavones \\
\hline \multirow{14}{*}{ 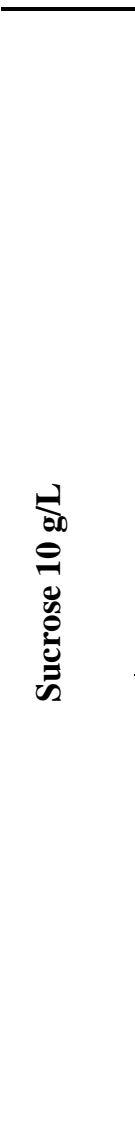 } & \multirow{8}{*}{$4 H R$} & 3 & $4.975 \pm 0.159 \mathrm{BCD}$ & $0.159 \pm 0.002 \mathrm{~K}$ & $4.049 \pm 0.180 \mathrm{CD}$ & $1.846 \pm 0.121$ FGHIJK & $11.029 \pm 0.116$ DEFGHIJ \\
\hline & & 3.5 & $2.942 \pm 0.059 \mathrm{BCDEFGH}$ & $0.110 \pm 0.001 \mathrm{~K}$ & $2.053 \pm 0.026 \mathrm{CD}$ & $0.708 \pm 0.013 \mathrm{JKLM}$ & $5.814 \pm 0.025$ GHIJKL \\
\hline & & 4 & $3.850 \pm 0.001 \mathrm{BCDEF}$ & $0.167 \pm 0.005 \mathrm{JK}$ & $2.294 \pm 0.049 \mathrm{CD}$ & $0.882 \pm 0.003$ IJKLM & $7.192 \pm 0.014$ FGHIJKL \\
\hline & & 4.5 & $1.906 \pm 0.052 \mathrm{EFGHI}$ & $0.625 \pm 0.001 \mathrm{DEFG}$ & $2.263 \pm 0.010 \mathrm{CD}$ & $1.388 \pm 0.027$ GHIJKLM & $6.182 \pm 0.022$ FGHIJKL \\
\hline & & 5 & $1.360 \pm 0.010 \mathrm{FGHI}$ & $0.448 \pm 0.004$ FGHIJK & $1.268 \pm 0.008 \mathrm{D}$ & $1.109 \pm 0.012$ HIJKLM & $4.185 \pm 0.008$ HIJKL \\
\hline & & 8 & $2.583 \pm 0.036 \mathrm{CDEFGHI}$ & $0.869 \pm 0.012 \mathrm{CDE}$ & $0.547 \pm 0.003 \mathrm{D}$ & $0.937 \pm 0.063$ HIJKLM & $4.937 \pm 0.029 \mathrm{HIJKL}$ \\
\hline & & 11 & $0.559 \pm 0.002 \mathrm{HI}$ & $0.533 \pm 0.003 \mathrm{EFGHI}$ & $0.400 \pm 0.006 \mathrm{D}$ & $1.707 \pm 0.144$ GHIJK & $3.199 \pm 0.039 \mathrm{IJKL}$ \\
\hline & & 14 & $0.313 \pm 0.027 \mathrm{HI}$ & $0.356 \pm 0.004$ FGHIJK & $0.548 \pm 0.001 \mathrm{D}$ & $1.312 \pm 0.119$ GHIJKLM & $2.529 \pm 0.038 \mathrm{JKL}$ \\
\hline & \multirow{6}{*}{$8 H R$} & 3 & $0.988 \pm 0.004 \mathrm{GHI}$ & $0.924 \pm 0.003 \mathrm{CD}$ & $3.521 \pm 0.024 \mathrm{CD}$ & $4.341 \pm 0.026 \mathrm{BCD}$ & $9.774 \pm 0.014$ DEFGHIJK \\
\hline & & 3.5 & $1.206 \pm 0.007 \mathrm{FGHI}$ & $1.326 \pm 0.005 \mathrm{~B}$ & $3.015 \pm 0.001 \mathrm{CD}$ & $4.373 \pm 0.003 \mathrm{BCD}$ & $9.921 \pm 0.004$ DEFGHIJ \\
\hline & & 4 & $2.479 \pm 0.011 \mathrm{DEFGHI}$ & $2.525 \pm 0.045 \mathrm{~A}$ & $3.938 \pm 0.004 \mathrm{CD}$ & $4.995 \pm 0.034 \mathrm{BC}$ & $13.938 \pm 0.024 \mathrm{CDEFG}$ \\
\hline & & 4.5 & $1.558 \pm 0.015 \mathrm{EFGHI}$ & $1.380 \pm 0.010 \mathrm{~B}$ & $0.499 \pm 0.028 \mathrm{D}$ & $0.795 \pm 0.008 \mathrm{JKLM}$ & $4.232 \pm 0.015$ HIJKL \\
\hline & & 5 & $1.057 \pm 0.024 \mathrm{GHI}$ & $1.165 \pm 0.010 \mathrm{BC}$ & $1.507 \pm 0.055 \mathrm{D}$ & $2.247 \pm 0.043 \mathrm{EFGHI}$ & $5.840 \pm 0.033$ GHIJKL \\
\hline & & 8 & $1.128 \pm 0.003 \mathrm{GHI}$ & $1.114 \pm 0.025 \mathrm{BC}$ & $1.397 \pm 0.006 \mathrm{D}$ & $3.175 \pm 0.023 \mathrm{DEF}$ & $6.815 \pm 0.014$ FGHIJKL \\
\hline \multirow{2}{*}{ 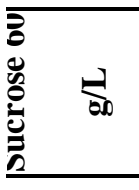 } & \multirow[t]{2}{*}{$4 H R$} & 3 & $1.536 \pm 0.305 \mathrm{EFGHI}$ & $0.404 \pm 0.029$ FGHIJK & $17.011 \pm 5.510 \mathrm{~A}$ & $4.354 \pm 0.740 \mathrm{BCD}$ & $23.306 \pm 1.646 \mathrm{AB}$ \\
\hline & & 3.5 & $12.774 \pm 1.332 \mathrm{~A}$ & $0.652 \pm 0.066 \mathrm{DEF}$ & $13.383 \pm 1.156 \mathrm{AB}$ & $1.075 \pm 0.199$ HIJKLM & $27.883 \pm 0.688 \mathrm{~A}$ \\
\hline
\end{tabular}




\begin{tabular}{|c|c|c|c|c|c|c|c|}
\hline & & 4 & $12.465 \pm 1.720 \mathrm{~A}$ & $0.620 \pm 0.061 \mathrm{DEFG}$ & $2.843 \pm 0.432 \mathrm{CD}$ & $0.147 \pm 0.076 \mathrm{LM}$ & $16.075 \pm 0.572 \mathrm{BCDE}$ \\
\hline & & 4.5 & $1.895 \pm 0.031 \mathrm{EFGHI}$ & $0.513 \pm 0.031$ FGHIJ & $15.184 \pm 5.289 \mathrm{~A}$ & $4.217 \pm 0.673 \mathrm{CD}$ & $21.808 \pm 1.561 \mathrm{ABC}$ \\
\hline & \multirow{4}{*}{$8 \mathrm{HR}$} & 3 & $4.184 \pm 0.164 \mathrm{BCDE}$ & $0.687 \pm 0.014 \mathrm{DEF}$ & $0.604 \pm 0.088 \mathrm{D}$ & $0.157 \pm 0.055 \mathrm{LM}$ & $5.461 \pm 0.080$ GHIJKL \\
\hline & & 3.5 & $1.937 \pm 0.298 \mathrm{EFGHI}$ & $0.395 \pm 0.009$ FGHIJK & $14.763 \pm 0.879 \mathrm{~A}$ & $4.114 \pm 0.302 \mathrm{CD}$ & $21.209 \pm 0.372 \mathrm{ABC}$ \\
\hline & & 4 & $5.397 \pm 0.271 \mathrm{~B}$ & $0.220 \pm 0.028 \mathrm{HIJK}$ & $7.973 \pm 1.031 \mathrm{BC}$ & $1.803 \pm 0.239$ FGHIJK & $14.943 \pm 0.392 \mathrm{BCDEF}$ \\
\hline & & 4.5 & $5.002 \pm 1.103 \mathrm{BCD}$ & $0.612 \pm 0.150 \mathrm{DEFG}$ & $2.054 \pm 0.467 \mathrm{CD}$ & $0.418 \pm 0.085 \mathrm{KLM}$ & $8.086 \pm 0.451 \mathrm{EFGHIJKL}$ \\
\hline \multirow{8}{*}{ 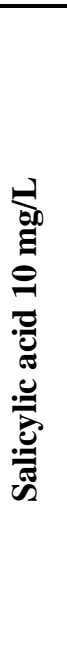 } & \multirow{4}{*}{$4 H R$} & 3 & $5.171 \pm 0.010 \mathrm{BC}$ & $0.301 \pm 0.028$ GHIJK & $3.526 \pm 0.118 \mathrm{CD}$ & $2.642 \pm 0.092 \mathrm{EFG}$ & $11.639 \pm 0.062$ DEFGHI \\
\hline & & 3.5 & $4.099 \pm 0.064 \mathrm{BCDE}$ & $0.208 \pm 0.008$ HIJK & $1.752 \pm 0.033 \mathrm{CD}$ & $1.503 \pm 0.112$ GHIJKL & $7.563 \pm 0.054$ EFGHIJKL \\
\hline & & 4 & $5.229 \pm 1.089 \mathrm{BC}$ & $0.239 \pm 0.011 \mathrm{HIJK}$ & $2.243 \pm 0.355 \mathrm{CD}$ & $1.276 \pm 0.183$ GHIJKLM & $8.987 \pm 0.410$ DEFGHIJKL \\
\hline & & 4.5 & $4.167 \pm 0.153 \mathrm{BCDE}$ & $1.153 \pm 0.019 \mathrm{BC}$ & $1.652 \pm 0.090 \mathrm{CD}$ & $1.513 \pm 0.076$ GHIJKL & $8.485 \pm 0.084$ DEFGHIJKL \\
\hline & & 3 & $3.618 \pm 0.617$ BCDEFG & $0.410 \pm 0.061$ FGHIJK & $5.867 \pm 0.866 \mathrm{CD}$ & $7.279 \pm 1.347 \mathrm{~A}$ & $17.174 \pm 0.723 \mathrm{BCD}$ \\
\hline & & 3.5 & $1.384 \pm 0.003 \mathrm{FGHI}$ & $0.202 \pm 0.002$ HIJK & $2.444 \pm 0.044 \mathrm{CD}$ & $3.463 \pm 0.002 \mathrm{DE}$ & $7.492 \pm 0.013$ EFGHIJKL \\
\hline & & 4 & $2.208 \pm 0.073 \mathrm{EFGHI}$ & $0.123 \pm 0.005 \mathrm{~K}$ & $1.556 \pm 0.016 \mathrm{D}$ & $2.036 \pm 0.034 \mathrm{EFGHIJ}$ & $5.923 \pm 0.032 \mathrm{GHIJKL}$ \\
\hline & & 4.5 & $2.327 \pm 0.561 \mathrm{DEFGHI}$ & $0.548 \pm 0.355 \mathrm{EFGH}$ & $1.220 \pm 0.133 \mathrm{D}$ & $1.335 \pm 0.170$ GHIJKLM & $5.181 \pm 0.306$ GHIJKL \\
\hline 武 & & 3 & $1.935 \pm 0.077 \mathrm{EFGHI}$ & $0.599 \pm 0.030 \mathrm{DEFG}$ & $1.379 \pm 0.085 \mathrm{D}$ & $1.324 \pm 0.086$ GHIJKLM & $5.237 \pm 0.070 \mathrm{GHIJKL}$ \\
\hline ల్ & $4 H R$ & 3.5 & $1.318 \pm 0.032 \mathrm{FGHI}$ & $0.167 \pm 0.008 \mathrm{JK}$ & $0.886 \pm 0.022 \mathrm{D}$ & $0.815 \pm 0.019$ IJKLM & $3.186 \pm 0.020 \mathrm{IJKL}$ \\
\hline 苞 & & 4 & $0.375 \pm 0.012 \mathrm{HI}$ & $0.397 \pm 0.003$ FGHIJK & $0.013 \pm 0.006 \mathrm{D}$ & $0.171 \pm 0.0002 \mathrm{LM}$ & $0.956 \pm 0.005 \mathrm{KL}$ \\
\hline 鹿 & & 4.5 & $0.172 \pm 0.016 \mathrm{I}$ & $0.155 \pm 0.001 \mathrm{~K}$ & $0.178 \pm 0.007 \mathrm{D}$ & $0.042 \pm 0.005 \mathrm{M}$ & $0.369 \pm 0.007 \mathrm{~L}$ \\
\hline
\end{tabular}




$\begin{array}{cclllll} & 3 & 0.836 \pm 0.011 \mathrm{HI} & 0.623 \pm 0.015 \mathrm{DEFG} & 0.294 \pm 0.010 \mathrm{D} & 0.564 \pm 0.047 \mathrm{KLM} & 2.307 \pm 0.021 \mathrm{JKL} \\ \boldsymbol{8} \boldsymbol{H R} & 3.5 & 1.626 \pm 0.020 \mathrm{EFGHI} & 0.165 \pm 0.014 \mathrm{JK} & 4.666 \pm 0.010 \mathrm{CD} & 5.740 \pm 0.012 \mathrm{~B} & 12.198 \pm 0.014 \mathrm{DEFGH} \\ & 4 & 1.726 \pm 0.019 \mathrm{EFGHI} & 0.198 \pm 0.007 \mathrm{IJK} & 1.889 \pm 0.058 \mathrm{CD} & 2.355 \pm 0.071 \mathrm{EFGH} & 6.167 \pm 0.039 \mathrm{FGHIJKL} \\ & 4.5 & 1.112 \pm 0.030 \mathrm{GHI} & 0.138 \pm 0.001 \mathrm{~K} & 0.631 \pm 0.006 \mathrm{D} & 0.896 \pm 0.007 \mathrm{IJKLM} & 2.776 \pm 0.011 \mathrm{JKL}\end{array}$

*Results are the mean of three replicates \pm SD and different letters in the same columns are significantly different at $P<0.05$, using Tukey test. 


\section{Tables}

\begin{tabular}{|c|c|c|c|c|c|}
\hline Cpd & $\mathrm{t}_{\mathrm{R}}^{\mathrm{a}}$ & Aglyc $\mathrm{MH}+^{\mathrm{b}}$ & $(m / z)^{\mathrm{c}}$ & Product ions $^{\mathrm{d}}$ & Identification $^{\mathrm{e}}$ \\
\hline 1 & 5.68 & 350 & 350 & - & $\mathrm{g}$ \\
\hline 2 & 5.84 & 350 & 350 & - & $\mathrm{g}$ \\
\hline 3 & 8.01 & 315 & 477 & 162 & $\begin{array}{l}\text { 3',7-Di-O-Methylorobol (5-Hydroxy-3-(4-hydroxy-3-methoxyphenyl)-7-methoxy-4H- } \\
\text { chromen-4-one) Hexose }\end{array}$ \\
\hline 4 & 8.23 & 285 & 447 & 162 & Biochanin/calycosin/maackiain/Glycitein/Prunetin/Texasin Hexose \\
\hline 5 & 9.3 & 315 & 563 & 248 & $\begin{array}{l}\text { 3',7-Di-O-Methylorobol (5Hydroxy-3-(4-hydroxy-3-methoxyphenyl)-7-methoxy-4H- } \\
\text { chromen-4-one) Malonyl Hexose }\end{array}$ \\
\hline 6 & 9.75 & 285 & 533 & 248 & Biochanin/calycosin/maackiain/Glycitein/Prunetin/Texasin - Malonyl Hexose \\
\hline 7 & 10.48 & 301 & 549 & 248 & $\begin{array}{l}\text { Pratensein/ } 3 \text { O Methylorobol (5,7-dihydroxy-3-(4-hydroxy-3-methoxyphenyl)-4Hchromen- } \\
\text { 4one) Malonyl Hexose }\end{array}$ \\
\hline 8 & 11.02 & 331 & 331 & - & $\mathrm{g}$ \\
\hline 9 & 11.14 & 269 & 431 & 162 & Formononetin - hexose \\
\hline 10 & 11.6 & 283 & 531 & 248 & Pseudobaptigenin- Malonyl hexose \\
\hline & 11.66 & 285 & 533 & 248 & Biochanin/calycosin/maackiain/Glycitein/Prunetin/Texasin - Malonyl Hexose \\
\hline
\end{tabular}




\begin{tabular}{|c|c|c|c|c|c|}
\hline 11 & 11.71 & 315 & 315 & - & $\begin{array}{l}\text { 3,7-Di-O-Methylorobol (5Hydroxy-3-(4-hydroxy-3-methoxyphenyl)-7-methoxy-4H- } \\
\text { chromen-4-one) }\end{array}$ \\
\hline 12 & 11.94 & 269 & 517 & 248 & Formononetine -Malonyl Hexose \\
\hline 13 & 12.05 & 283 & 531 & 248 & Pseudobaptigenin- Malonyl Hexose \\
\hline 14 & 12.33 & 285 & 285 & - & Biochanin/calycosin/maackiain/Glycitein/Prunetin/Texasin \\
\hline 15 & 12.41 & 269 & 517 & 248 & Formononetin -Malonyl Hexose \\
\hline 16 & 13.26 & 285 & 533 & 248 & Biochanin/calycosin/maackiain/Glycitein/Prunetin/Texasin - Malonyl Hexose \\
\hline 17 & 13.52 & 299 & 547 & 162 & Irilone/Afrormosine-Malonyl Hexose \\
\hline 18 & 13.54 & 301 & 549 & 248 & $\begin{array}{l}\text { Pratensein/ } 3 \text { O Methylorobol (5,7-dihydroxy-3-(4-hydroxy-3-methoxyphenyl)-4Hchromen- } \\
\text { 4one) Malonyl Hexose }\end{array}$ \\
\hline 19 & 14.41 & 285 & 533 & 248 & Biochanin/calycosin/maackiain/Glycitein/Prunetin/Texasin - Malonyl Hexose \\
\hline 20 & 14.58 & 301 & 301 & - & $\begin{array}{l}\text { Pratensein/ } 3 \text { O Methylorobol (5,7-dihydroxy-3-(4-hydroxy-3-methoxyphenyl)-4Hchromen- } \\
\text { 4one) }\end{array}$ \\
\hline 21 & 15.51 & 283 & 283 & - & Pseudobaptigenin \\
\hline 22 & 15.92 & 269 & 269 & - & Formononetin \\
\hline 23 & 17.29 & 299 & 299 & & Irilone/Afrormosine \\
\hline 24 & 18.29 & 307 & 365 & - & $\mathrm{g}$ \\
\hline 25 & 18.51 & 285 & 285 & & Biochanin A \\
\hline 26 & 19.36 & 269 & 372 & 103 & Formononetine Malonyl \\
\hline
\end{tabular}


${ }^{\mathrm{a}}$ rT: retention time in minutes; Cpd: Compound.

${ }^{\mathrm{b}}$ Aglycone MH+: molecular ion weight provided by ESI-MS in a positive mode after the loss of the sugar molecule.

${ }^{\mathrm{c}} \mathrm{m} / \mathrm{z}:[\mathrm{M}+\mathrm{H}]^{+}$: molecular ion weight provided by ESI-MS in a positive mode.

${ }^{\mathrm{d}}$ Product ions: fragment obtained by MS/MS with the collision energy.

${ }^{\mathrm{e}}$ Identification: suggested structure of the compound based on rT and the m/z confirmed with a standard (data in bold) or from MS and MS/MS spectra deduction.

${ }^{\mathrm{f}}$ References: studies with the identification of the compound.

${ }^{\mathrm{g}}$ Compound not identified. 


\section{Figure Captions:}

Fig. 1 Isoflavonoids biosynthetic pathway showing the general phenylpropanoid metabolic pathway and the isoflavone pathway with the most known molecules: daidzein (a), genistein (b), formononetin (c), biochanin A (d) and the estrogen 17ß-estradiol (e) for molecular comparison. The majority of isoflavone molecules are formed by a split pathway, according to their key intermediates. Genistein originates through naringenin and subsequently, via isoflavone 4'-O-methyltransferase enzyme generates biochanin A. For daidzein, the intermediate is liquiritigenin and with the action of the same isoflavone 4'-Omethyltransferase it gives formononetin. Adapted from (Du et al. 2010; Kanehisa et al. 2017)

Fig. 2 Root growth (mm) after seven days of culture in MS medium containing different concentrations of (a) sucrose + agar or phytagel, (b) salicylic acid, (c) yeast extract and (d) flagellin 22. Results are the mean of three replicates \pm SD and different letters in the same treatment are significantly different at $P<0.05$ (Tukey test). The red bar represents the root growth of control conditions (sucrose $10 \mathrm{~g} / \mathrm{L}$ with agar)

Fig. 3 Isoflavone content (mg/g dry plants) of $T$. pratense seedlings cultivated in medium with agar or phytagel as gelling agent (different concentration) and with elicitors at different concentrations. Seedlings were grown for seven days following germination on these different media before isoflavonoid content measurement. Panel (a) sucrose + phytagel or agar, panel (b) salicylic acid, panel (c) yeast extract and panel (d) flagellin 22. Results are the mean of three replicates \pm SD and different letters in the same treatment are significantly different at $P<0.05$ (Tukey test). The red bar represents the isoflavone content in control conditions (sucrose $10 \mathrm{~g} / \mathrm{L}$ with agar, panel a) 
Fig. $4 T$. pratense A. rhizogenes induced hairy root production. (a) Seedlings 10 days after infection. (b) Roots transferred to the medium without growth regulators, 30 days after the induction. (c) Development of the roots after 1 week on solid medium. (d) Transfer to liquid medium, 50 days after infection. (e) and (f) Hairy root after one week in liquid medium (above and below of the bottle). (g) and (h) The hairy root culture after 3 weeks in liquid medium

Fig. 5 Graphic representation of the $T$. pratense hairy root line isoflavonoid profiles represented as the percentage of the total flavonoid content. Each isoflavonoid compound is represented by a different colour and the percentage of the molecule is indicated in the corresponding part of the bar. The colour code is given on the right part of the figure. Note that each line has a specific isoflavonoid composition. Values below $3 \%$ were removed from the graph representation

Fig. 6 Isoflavones content of the T. pratense HR lines $1 \mathrm{HR}, 2 \mathrm{HR}, 4 \mathrm{HR}$ and $6 \mathrm{HR}$ during the first 5 months of culture. (a) Daidzein; (b) Genistein; (c) Formononetin and (d) Biochanin A contents. The total isoflavonoid production is given in (e). The results are the mean of three replicates \pm SD and different letters in the same isoflavone analysis are significantly different at $P<0.05$ (Tukey test). The colour code is indicated on the right side of the last panel

Fig. 7 Effect of sucrose $10 \mathrm{~g} / \mathrm{L}$ (control, a-b) and $60 \mathrm{~g} / \mathrm{L}$ (c-d), salicylic acid $10 \mathrm{~g} / \mathrm{L}$ (e-f) and $30 \mathrm{mg} / \mathrm{L}(\mathrm{g}-\mathrm{h})$ on the accumulation of major and total isoflavones $T$. pratense hairy roots. Line 4HR (a-c-e-g) and line 8HR (b-d-e-h). Results are the mean of three replicates \pm SD and different letters in the same isoflavone detected are significantly different at $P<0.05$ (Tukey test). The time is represented in days 
Fig. S1 Colour modification in the T. pratense plantlets flavonoid extracts cultivated in presence of Sucrose plus phytagel as gelling agent. From left to right extracts of cultures grown on $10,30,60,90$ and $120 \mathrm{~g} / \mathrm{L}$ of sucrose 


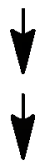

Flavonoid

biosynthesis<smiles>O=C1C[C@H](c2ccc(O)cc2)Oc2cc(O)ccc21</smiles>

$\mid \begin{gathered}2- \\ \text { hydroxyisof lavanone } \\ \text { synthase }\end{gathered}$<smiles>O=C1c2ccc(O)cc2OC(O)C1c1ccc(O)cc1</smiles>

2,7,4'-Trihydroxyisof lavanone

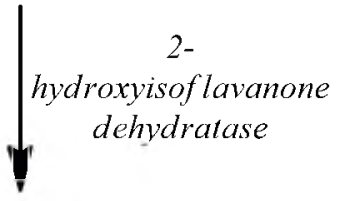

$\mathrm{HO}$<smiles>O=c1c(-c2ccc(O)cc2)coc2cc(F)ccc12</smiles>

Daidzein (a)

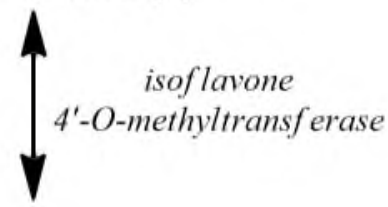

HO<smiles>COc1ccc(-c2coc3cc(C)ccc3c2=O)cc1</smiles>

Formononetin (c)<smiles>O=C1C[C@H](c2ccc(O)cc2)Oc2cc(O)cc(O)c21</smiles>

$2-$ hydroxyisof lavanone synthase

$\mathrm{HO}$<smiles>O=C1c2c(O)cc(I)cc2OC(O)C1c1ccc(O)cc1</smiles>

2-Hydroxy-2,3-dihydrogenistein $2-$ hydroxyisof lavanone dehydratase

$\mathrm{HO}$<smiles>Cc1cc(O)c2c(=O)c(-c3ccc(O)cc3)coc2c1</smiles>

Genistein (b)

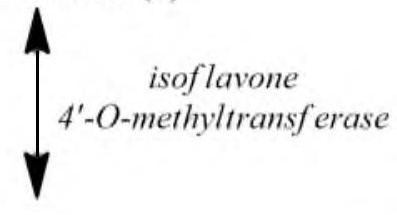

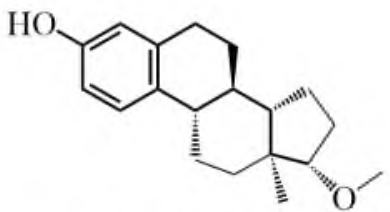

$17 \beta$-estradiol (e)<smiles>COc1ccc(-c2coc3cc(O)cc(O)c3c2=O)cc1</smiles>

Biochanin A (d) 


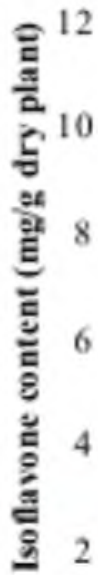

0

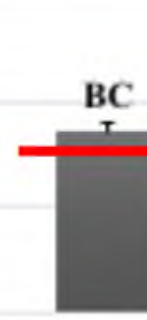

b

1,4

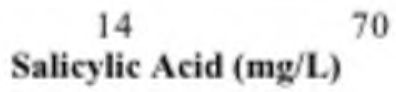
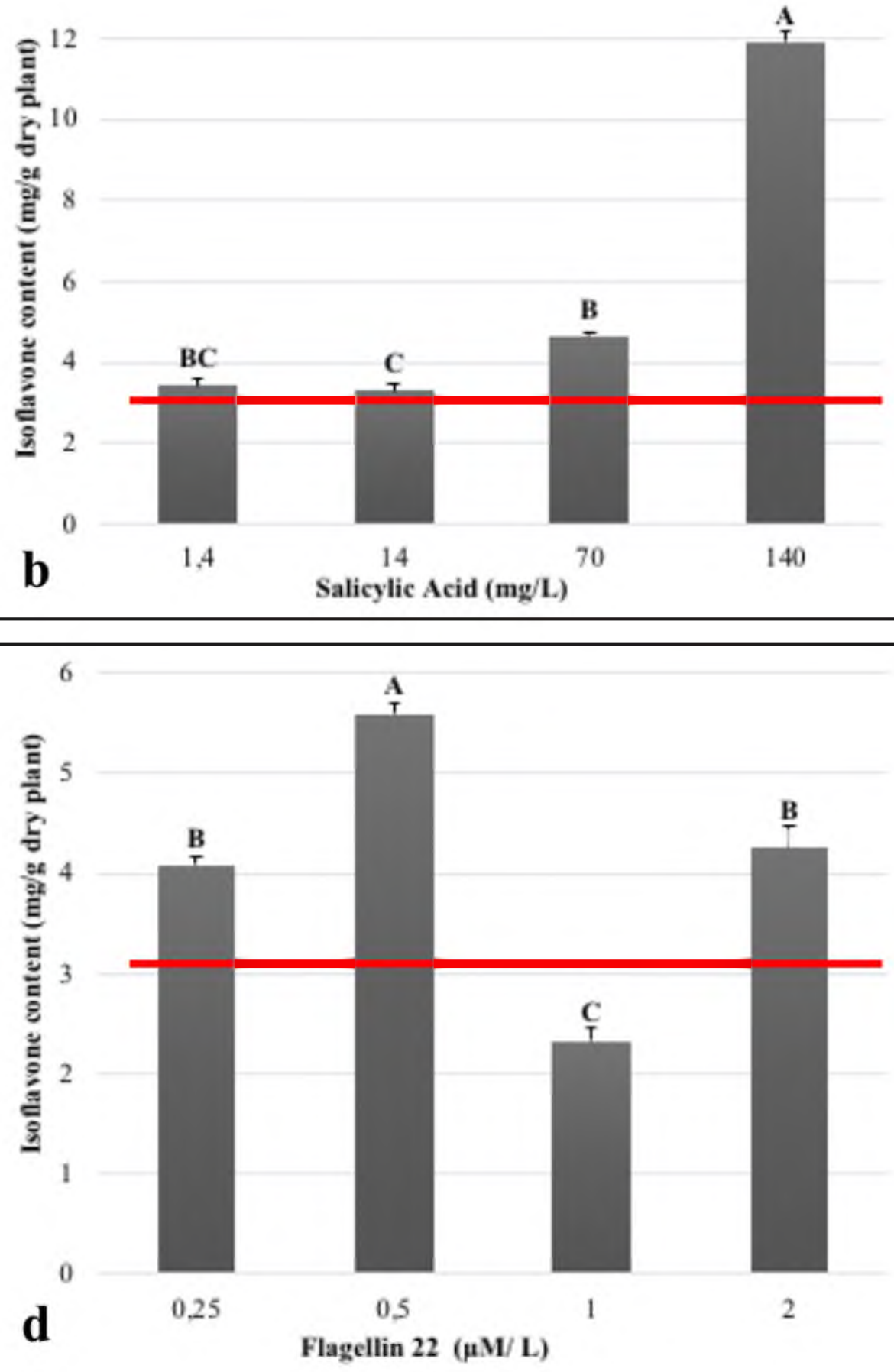


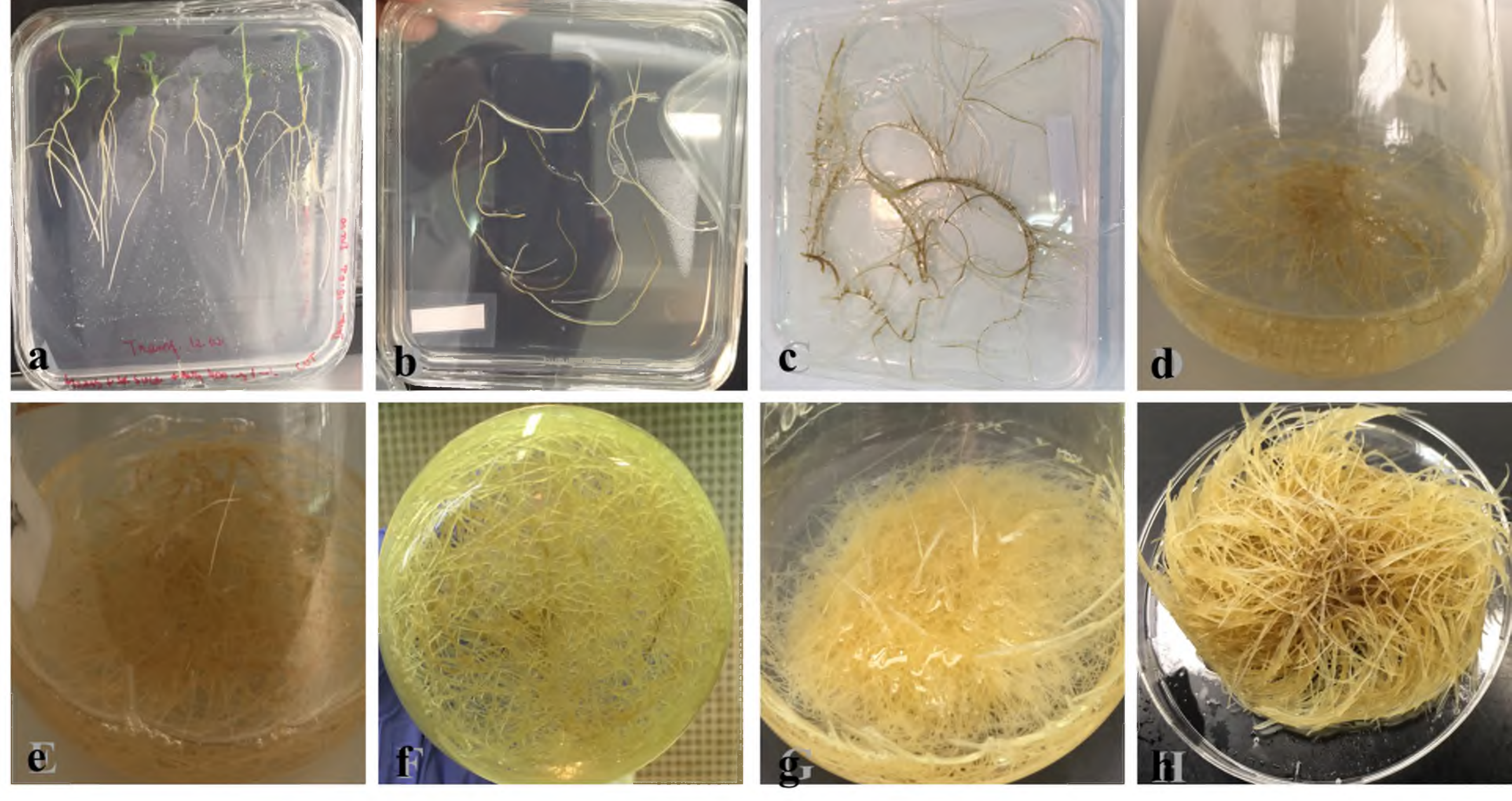




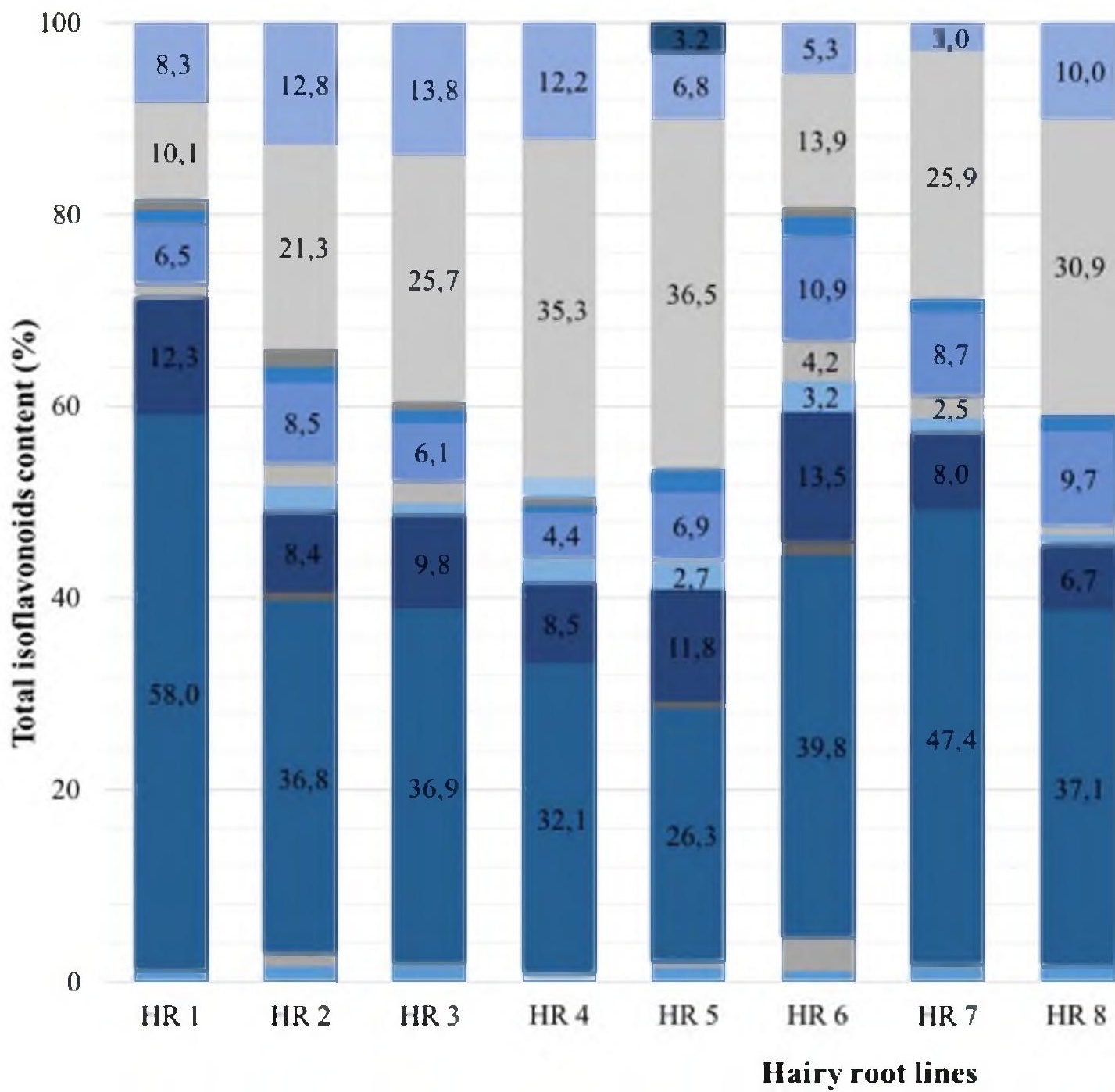




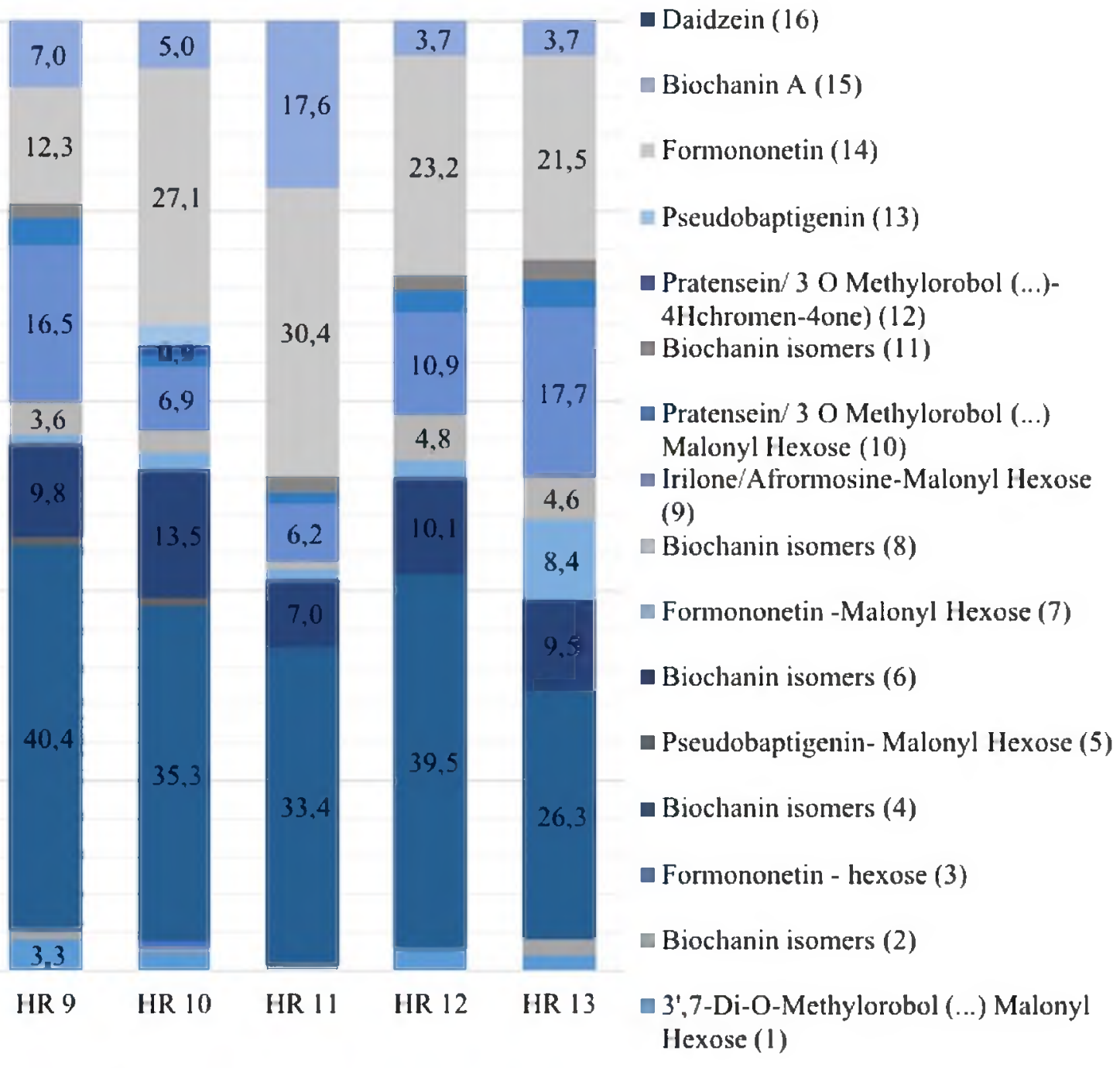


(2) Total isolavonoids content (mg/g dry plant)

○ ๒

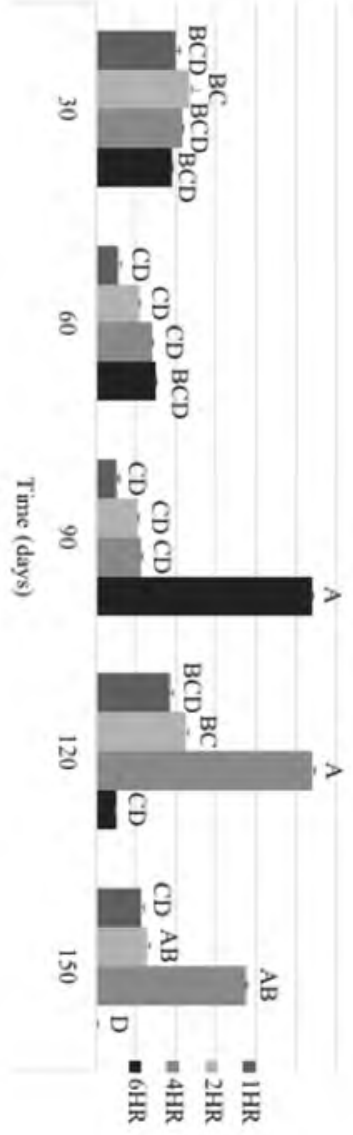

2. Biochanin $A$ (ne/g dry roots)

S

- u $\bar{\sigma} \bar{u}$ :

w

ह

६

$\bar{g}$ 
Formononetin (mg/g dry roots) .)

u $\bar{\sigma}$ है
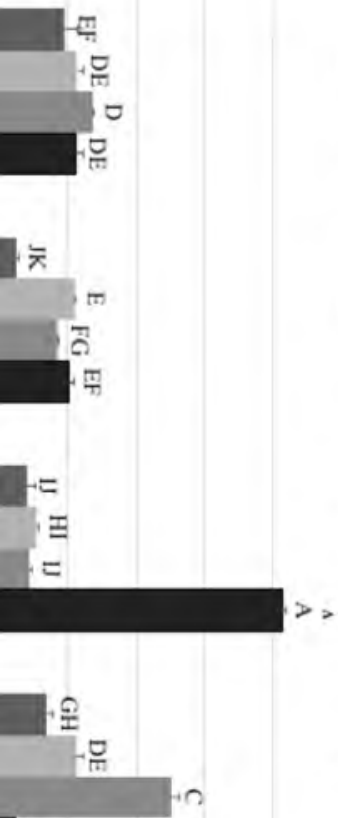

$\check{\pi}$

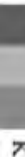

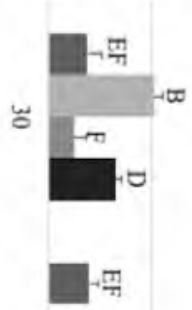
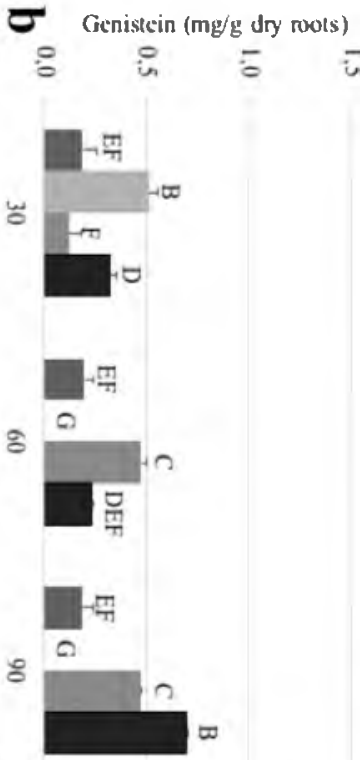

o in in

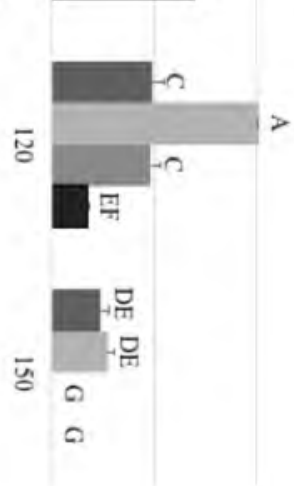

D) Daidzein (mg/g dry mots)

$\therefore$ in is is

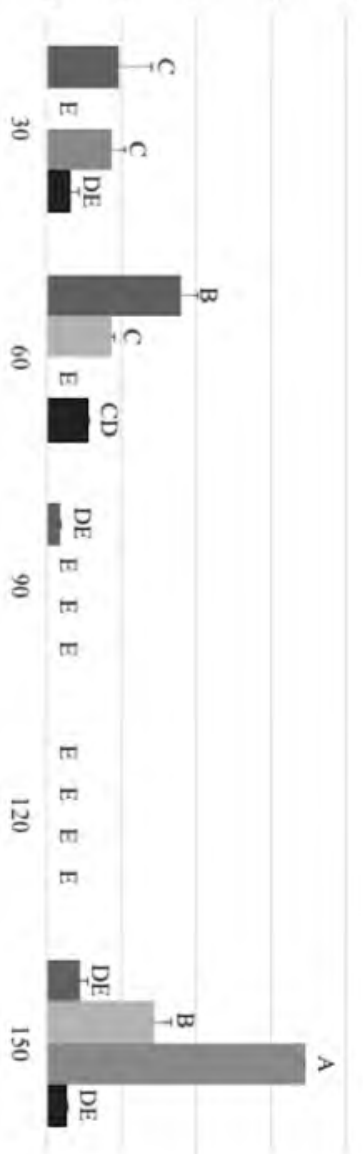




S10P $\frac{3308}{\text { (1) }} \frac{5600}{\text { (3) }}$

